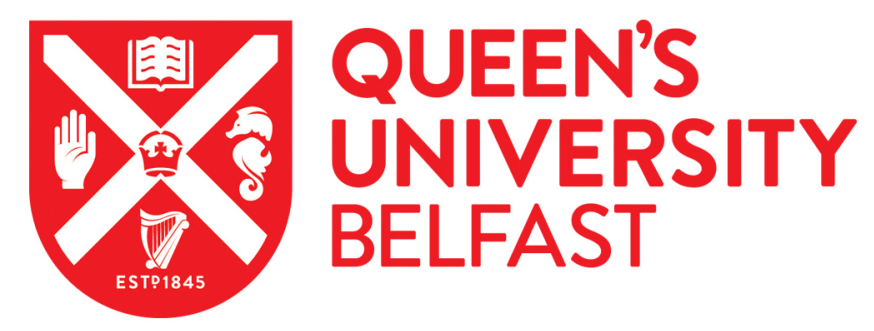

\title{
Electroless nickel, alloy, composite and nano coatings - A critical review
}

Sudagar, J., Lian, J., \& Sha, W. (2013). Electroless nickel, alloy, composite and nano coatings - A critical review. Journal of Alloys and Compounds, 571, 183-204. https://doi.org/10.1016/j.jallcom.2013.03.107

\section{Published in:}

Journal of Alloys and Compounds

\section{Document Version:}

Peer reviewed version

\section{Queen's University Belfast - Research Portal:}

Link to publication record in Queen's University Belfast Research Portal

\section{Publisher rights}

Copyright 2013 Elsevier.

This manuscript is distributed under a Creative Commons Attribution-NonCommercial-NoDerivs License

(https://creativecommons.org/licenses/by-nc-nd/4.0/), which permits distribution and reproduction for non-commercial purposes, provided the author and source are cited.

\section{General rights}

Copyright for the publications made accessible via the Queen's University Belfast Research Portal is retained by the author(s) and / or other copyright owners and it is a condition of accessing these publications that users recognise and abide by the legal requirements associated with these rights.

\section{Take down policy}

The Research Portal is Queen's institutional repository that provides access to Queen's research output. Every effort has been made to ensure that content in the Research Portal does not infringe any person's rights, or applicable UK laws. If you discover content in the Research Portal that you believe breaches copyright or violates any law, please contact openaccess@qub.ac.uk. 


\section{ELECTROLESS NICKEL, ALLOY, COMPOSITE AND NANO \\ COATINGS - A CRITICAL REVIEW}

Jothi Sudagar

Department of Metallurgical and Materials Engineering, Indian Institute of Technology-

Madras (IIT-M), Chennai - 600 036, India

Jianshe Lian

College of Materials Science and Engineering, Jilin University, Changchun 130025, China.

Wei Sha*

School of Planning, Architecture and Civil Engineering, Queen's University Belfast, Belfast BT7 INN, UK.

*Corresponding author. Tel: +44 28 90974017; fax: +44 28 90974278; e-mail: w.sha@qub.ac.uk

\section{Abstract}

The development of metal deposition processes based on electroless nickel, alloy and composite coatings on various surfaces has witnessed a surge in interest among researchers, with many recent applications made possible from many excellent properties. In recent years, these coatings have shown promising corrosion and wear resistance properties and large number of newer developments became most important from macro to nano level 
applications. After a brief review of the fundamental aspects underlying the coating processes, this paper discusses in detail about different electroless nickel alloy, composite, nano plating, bath techniques, preparation, characterization, new depositing mechanism and their recent applications, including brief notes on difficult substrate and waste treatment for green environment. Emphasis will be on to their recent progress, which will be discussed in detail and critically reviewed.

Keywords: Electroless nickel; Electroless composite; Electroless nickel-phosphorus/boron alloy coatings; Electroless nano-coating.

\section{Introduction}

\subsection{Preamble}

Electroless process is an autocatalytic method in which the reduction of the metallic ions in the solution and the film deposition can be carried out through the oxidation of a chemical compound present in the solution itself, i.e., reducing agent, which supplies an internal current. The process requires that a cation of the metal to be deposited is reduced by the receiving electrons, from the surface of a metal substrate or from the surface of the catalysts used to initiate the deposition. The reductant in turn delivers electrons to this surface and is thereby oxidized.

The autocatalytic or chemical reduction of aqueous metal ions coated to a base substrate without passage of external current is referred as electroless plating ${ }^{[1-2]}$. It excludes, however, the process used to deposit without current, such as, immersion plating (copper deposited on the steel immersed in the copper sulfate solution or nickel on the steel immersed in chloride and boric acid bath) and homogenous chemical reduction process (silvering). In galvanic displacement or immersion plating, the base material is dissolved into the solution; meanwhile, the metallic ions in the solution are reduced on the surface of the base material. 
Such a mechanism differs from the autocatalytic deposition because, in the immersion plating, the reducing agents are not required to reduce the metal ions to metal, as the base material itself behaves as a reducing agent. However, these processes have not gained wide acceptance, as it has poor adherence and poor properties. Electroless coating process has gained wide acceptance in the market due to the coatings' excellent corrosion and wear resistance properties and it is also good for soldering and brazing purposes.

The difference of electroless plating process ${ }^{[3-4]}$ from the immersion plating ${ }^{[5]}$ is that the deposition of metal is autocatalytic reduction process and electroless plating does not use electrodes, and is an autocatalytic reaction on the metal surface after nucleation has begun. An immersion plating solution, on the other hand, operates on the principle of displacement of the surface skin of the substrate by a more noble metal that is in solution. Even if they are generally grouped together under the electrochemical methods or electro deposition processes, distinctions between electrolytic and electroless deposition processes must be made, as illustrated in Fig. 1.
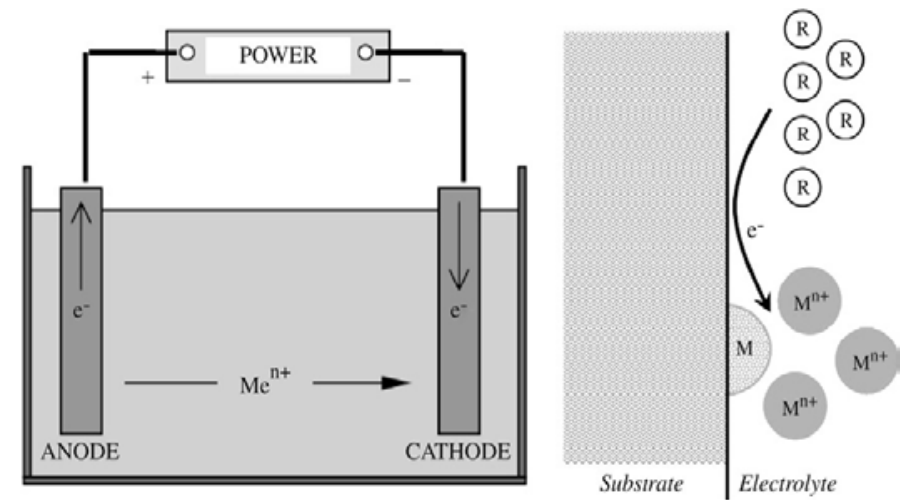

Fig. 1. Cell set up for (left side) electrolytic deposition process plus external power source; (right side) electroless deposition with reducing agent $\mathrm{R}$ as the source of electrons ${ }^{[6]}$. Electroless has several advantages over electroplating technique, except the life of the bath. The advantages include the quality of the deposit, namely the physical and mechanical properties. In this process, a sharp edge receives the same thickness of deposit as a blind hole does and it offers extremely bright deposits, which are comparable with electroplated bright 
nickel. The desirable properties can be varied by choosing different $\mathrm{pH}$, temperature and composition of the bath. Electroless nickel coatings has assumed the greatest commercial importance among the electroless coating. General categories of the electroless nickel coatings are shown in Fig. 2.

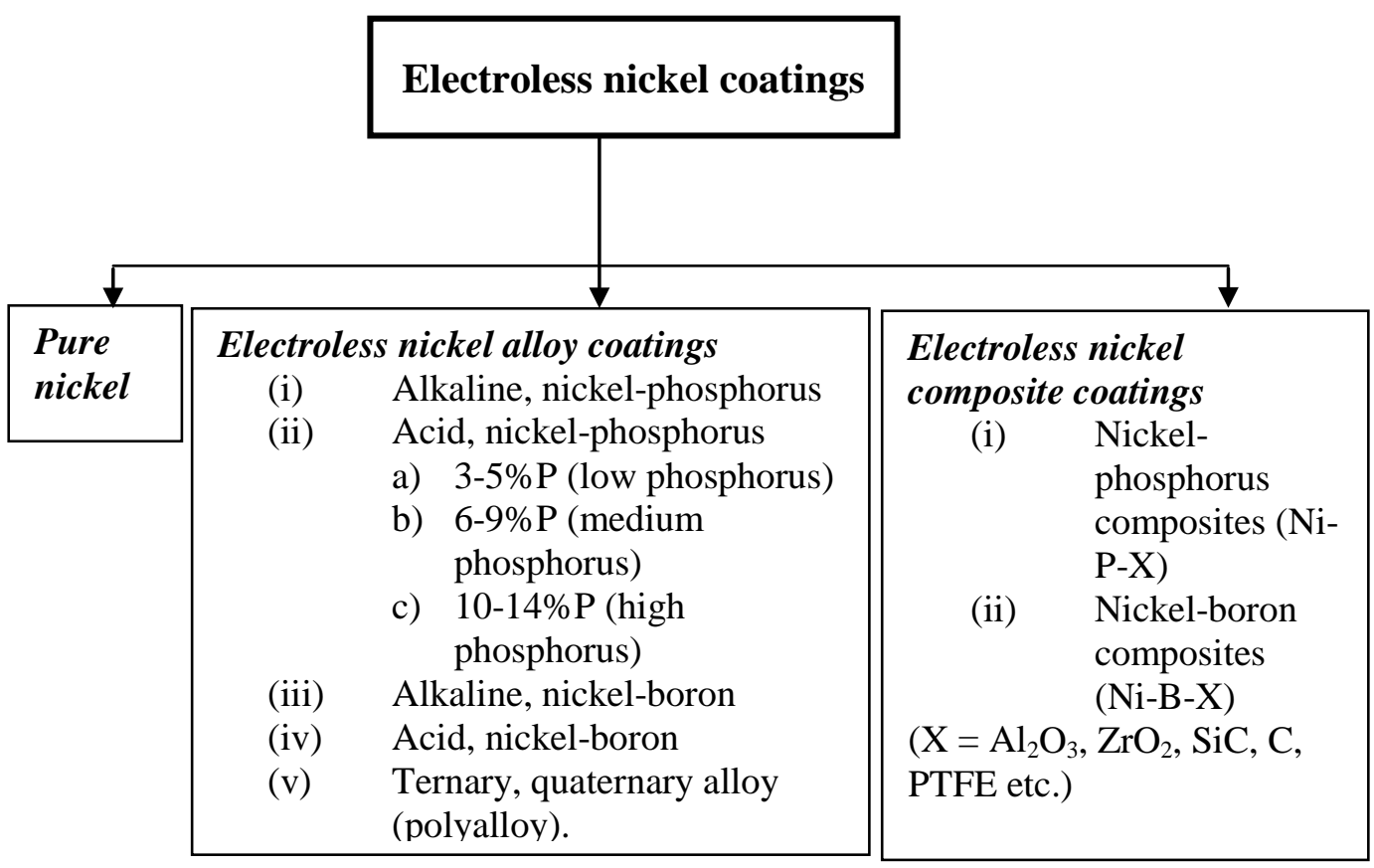

Fig. 2. General categories of electroless nickel coatings.

In general, electroless plating bath contains a source of metal ions, reducing agent, complexing agent, stabilizer, buffering agent, wetting agent, and its parameters include controlled temperature and $\mathrm{pH}$. Their role is briefly summarized in Table 1 . The process of electroless deposition is one of the most elegant methods available for the deposition of alloy coatings. The technique involves autocatalytic reduction, at the substrate/solution interface of cations by electrons released from the suitable reducing chemicals ${ }^{[7]}$ and significant degree of elemental release from these agents allowing co-deposition of reduced metal, in order to produce binary, ternary or even quaternary alloys ${ }^{[8-9]}$. The co-deposition of composite materials in the alloy coating leads to electroless composite coatings. 
Table 1: Components and parameters of bath and their functions

\begin{tabular}{ll}
\hline Component/parameter & Function \\
\hline Metal ions & Source of metal \\
Reducing agents & Supply electrons to reduce the metal ions \\
Complexants & Prevent excess of free metal ions concentration \\
Accelerators & Accelerate the reducing agent and increase the deposition \\
Stabilizers & Stabilize the bath from decomposition by shielding catalytically \\
& Sustain the pH for long time \\
Buffers & pH adjustment \\
pH regulators & Energy for deposition \\
Temperature &
\end{tabular}

In electroless plating technique many metals like nickel, copper, gold, silver, palladium and cobalt are being deposited. The industrial uses of electroless nickel especially the nickel/phosphorus alloy has grown steadily during the last decade, because of its unique properties. The autocatalytic deposition of almost pure nickel using hydrazine as the reducing agent has been known for many years, but this process has found little industrial usage. The nickel/phosphorus or boron alloys are mostly regarded as synonymous for the word 'electroless' because 95\% of industrial productions are of these alloys. In recent years, electroless plating has attracted attention due to its application in the fields of engineering ${ }^{[10]}$, surface science ${ }^{[11]}$, separation and purification technology ${ }^{[12]}$ and its virtues ${ }^{[13]}$.

\subsection{Historical overview}

The electroless deposition of metallic nickel from aqueous solution in the presence of hypophosphite was first noted as a chemical accident by Wurtz in $1844^{[14-15]}$. In 1911, Roux reported that metal was inevitably precipitated in the powder form; however these works 
were not in practical applications. In its early stage, progress in the field remained slow until World War II. In 1946, Brenner and Riddell developed a process for plating the inner walls of tubes with nickel-tungsten alloy, derived from the citrate based bath using an insoluble anode, which brought out the unusual reducing properties of hypophosphite. The U.S. Patent Office says that the patent it issued in 1950 differed from the earlier patent in that Roux reaction was spontaneous and complete, while the Brenner and Riddell process was a controlled catalytic process so that deposition occurred only on catalytic surfaces immersed in the bath. Brenner later wrote that his patent was an accidental discovery similar to the work of Wurtz and Roux, but said that he took out a patent to protect U.S. government rights. In fact, a declassified U.S. Army technical report written in 1963 goes on extensively about Wurtz and Roux work, and gives more of the discovery credit to them than to Brenner. This plating process was attributed to the action of chemical reduction of $\mathrm{Ni}$ ions ${ }^{[16]}$.

During the 1954-59 period, Gutzeit ${ }^{[17-19]}$ at GATC (General American Transportation Corporation) worked on full scale development of electroless plating by chemical reduction alone, as an alternate process to conventional electroplating. His research has been considered as the new scientific basis for modern electroless deposition. The earlier work on electroless nickel was exclusively based on alkaline bath. Later, the advantages afforded by the use of acidic baths have received greater attention. It was found that acidic bath was chemically more stable and promotes finer bath control. Initially, the co-deposition of particles was carried out for electrodepositing nickel-chromium by Odekerken ${ }^{[20-21]}$, during the year of 1966. In that study, in an intermediate layer, finely powdered particles like aluminum oxide, polyvinyl chloride (PVC) resin were distributed within a metallic matrix. A layer in the coating is composite but other parts of the coating are not. Further, according to Ref. [22], Metzger et al. initiated electroless nickel coatings containing alumina $\left(\mathrm{Al}_{2} \mathrm{O}_{3}\right)$ particles of micron size, during the year of 1966, though Ref. [22] did not provide an original reference 
by Metzger et al. for this statement. The first commercial application of their work used the electroless $\mathrm{Ni}$-SiC coatings on the wankel internal combustion engine and another commercial composite incorporating polytetrafluoroethylene (Ni-P-PTFE) was co-deposited, during the year of 1981. However, the co-deposition of diamond and PTFE particles was more difficult, than the composites incorporating $\mathrm{Al}_{2} \mathrm{O}_{3}$ or $\mathrm{SiC}{ }^{[23]}$. The feasibility to incorporate the fine second phase particles, in submicron to nano size, within a metal/alloy matrix has initiated a new generation of composite coatings.

Electroless nickel is not pure metal but includes other element(s) also derived from the reducing agent, such as phosphorus or boron, or elements such as thallium, lead or cadmium derived from other bath additives. Further advances in early 1980's, phosphorus rich deposits from acidic bath gave higher wear and corrosion resistance than those produced under alkaline conditions, without heavy metal stabilizers. These coatings look like glassy, amorphous structures and consist of extremely small $(\sim 5 \mathrm{~nm})$ crystallites, whereas others are believed to be truly amorphous containing no discernible short-range order. Electroless nanocoatings are defined to have either the thickness of the coating or the second phase particles that are dispersed into the matrix in the range of nano level ${ }^{[22]}$. Electroless copper coating was being used before electroplating on plastics, ceramics, polymers and other nonconducting materials and then the rest of electroless metallic deposits was followed. Since then the electroless coating chemistry has emerged as one of the thrust areas of the surface engineering and metal finishing research ${ }^{[13,22,24-26]}$.

\subsection{Synopsis}

Following this introduction section, this review will, in Section 2, make a brief discussion of fundamental aspects underlying electroless coating processes, providing a baseline against which to discuss about the different electroless nickel bath in Section 3. We 
briefly discuss the pure, black nickel and point the reader to the references, where they are discussed in more detail. In Section 3, we discuss in detail about different electroless nickel alloy plating and its bath techniques, preparation, characterization, new depositing mechanism. Section 4 explains the review of properties, where we compare the properties of nickel-phosphorus and nickel-boron. Composite and nano coatings are the topics for the next two sections, Sections 5 and 6, respectively. Section 7 gives brief notes on plating on difficult substrate and waste treatment. Finally, in Section 8, the review ends with conclusion and future scope.

\section{Fundamental aspects of electroless}

The basic requirement for an electroless bath includes metal ions/its concentration, reducing agent(s), complexing agent(s), bath stabilizer(s), control of $\mathrm{pH}$ and temperature. In electroless deposition, metal ions are reduced to metal by the action of chemical reducing agents, which are simply electron donors. The metal ions are electron acceptors, which react with electron donors. It is an autocatalytic process, which accelerates the electroless chemical reaction allowing oxidation of the reducing agent used. Fig. 3 shows the basic diagram of the apparatus usually used in electroless experiments.

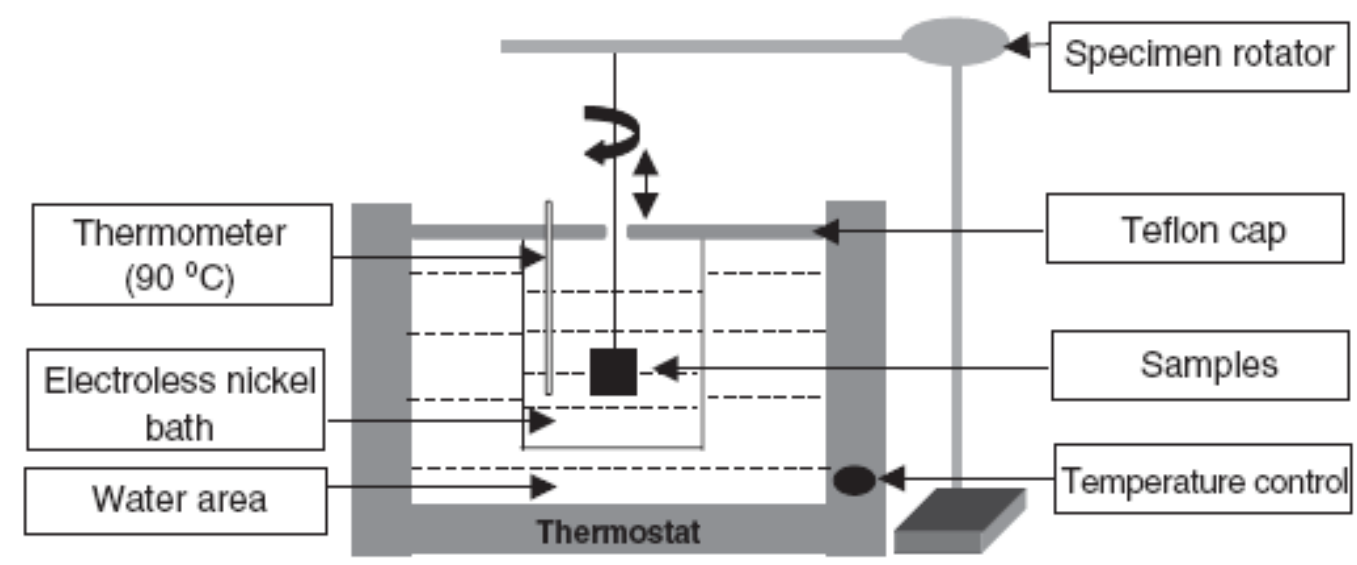

Fig. 3. Basic diagram of the apparatus usually used in electroless experiments ${ }^{[27]}$. 


\subsection{Reducing agent}

Many reducing agents have been commercialized including sodium hypophosphite, amino boranes, sodium borohydride, and hydrazine (Table 2). DMAB, though not in Table 2, is one kind of amino boranes, which was explained in Section 2.1.2.

\subsubsection{Sodium hypophosphite baths}

Electroless deposition with hypophosphite bath has advantage over boron and hydrazine reduced baths. The hypophosphite bath costs lower and gives better corrosion resistance.

The reduction mechanism of metal ions by hypophosphite involves two reactions, i.e., hypophosphite ions are catalytically oxidized and nickel ions are reduced at the catalytic surface. A part of released hydrogen is absorbed onto the catalytic surface and this is an anodic reaction. The nickel ion at the surface of the catalyst is then reduced by the absorbed active hydrogen and this is a cathodic reaction. Gould et al. ${ }^{[28]}$ and Marshall ${ }^{[29]}$ have found that the deposition reaction does not depend on the chemical reduction, but it is controlled by an electrochemical mechanism. In this mixed potential theory, the overall electroless deposition mechanism is interpreted in terms of anodic and cathodic partial electrochemical reaction ${ }^{[30]}$. Some absorbed hydrogen reduces small amount of the hypophosphite to water, hydroxyl ion and phosphorus. Most of the hypophosphite present is catalytically oxidized to the orthophosphate and gaseous hydrogen independently of the deposition of the nickel and phosphorus. In general, $1 \mathrm{~kg}$ of sodium hypophosphite is needed to reduce $200 \mathrm{~g}$ of nickel, for an average efficiency of $37 \%{ }^{[31-32]}$. Electroless nickel coatings has assumed the greatest commercial importance and discussed everywhere predominately. 


\subsubsection{Amino boranes baths}

There are two types of aminoboranes in commercial use, namely N-dimethyl amine borane (DMAB) and N-diethyalmine borane (DEAB). They are effective reducing agents over a wider range of $\mathrm{pH}$ compared to the borohydrides ${ }^{[33-34]}$. Nickel baths with amino boranes can work in both acid and alkaline baths. The overall reduction reactions produce metallic nickel, and nickel boride.

In general, $1 \mathrm{~kg}$ of dimethylamine borane is needed to reduce $1 \mathrm{~kg}$ of nickel ${ }^{[14]}$. Amine boranes can be used as a good reducing agent for plating plastics, non-metals and also for electroless deposition of other metals such as copper, gold, silver, and cobalt.

\subsubsection{Sodium borohydride baths}

It is the most powerful reducing agent available for the electroless nickel plating. In acid and neutral $\mathrm{pH}$ ranges, borohydrides are readily hydrolyzed and in the presence of nickel ions, nickel boride is formed. In alkaline solutions ( $\mathrm{pH}$ above 13), borohydride is catalytically decomposed. In the presence of nickel ions, nickel boride is formed.

In general, $600 \mathrm{~g}$ of sodium borohydride is needed to reduce $1 \mathrm{~kg}$ of nickel and the nickel deposits are more than $92.97 \%$ pure. Spontaneous solution decomposition may occur, if the bath $\mathrm{pH}$ is allowed to fall below 12. Because of the high operating $\mathrm{pH}$, borohydride plating baths cannot be used for aluminum substrates.

\subsubsection{Hydrazine bath}

Hydrazine bath has been used to produce pure electroless nickel deposition (99\%). Because of its instability at high temperatures, however these baths tend to be very unstable and difficult to control also. In pure nickel section, more details will be discussed. 


\subsection{Complexing agent}

Complexing agents are added to prevent the decomposition of solutions and to control the reaction so that it occurs only on the catalytic surface. Complexing agents are organic acids or their salts, added to control the amount of free electron (nickel) available for reaction. Complexing agents also buffer the solution and retard the precipitation of nickel phosphite. Ammonia, hydroxides, or carbonates may also have to be added periodically to neutralize hydrogen. The complexing agent used in the plating solution can also have an effect on the quality of the deposit, especially on its phosphorus content, internal stress and porosity.

\subsection{Accelerator}

They are often added to the plating solution in small amounts to increase the speed of the deposition and can cause the plating rate to become economically high. Accelerator's main function is to lose the bond between hydrogen and phosphorus atoms in the hypophosphite molecule, allowing phosphorus to be more easily removed and absorbed onto the catalytic surface. In hypophosphite-reduced solutions, though not listed in Table 2, succinic acid is also used as an accelerator most frequently.

\subsection{Inhibitor and by-products}

The addition of inhibitors, also called stabilizers, as in Table 2, can have harmful as well as beneficial effects on the plating bath and its deposit. In small amounts, some inhibitors increase the rate of deposition and the brightness of the deposit. The substrate should be catalytic in nature. If it is not, then one has to make surface catalytic by proper pretreatment followed by immersion into the electroless bath whereby a uniform deposition begins. Once it gets deposited it will acts as catalyst and the process continues. During electroless nickel deposition, by-products of the reduction, orthophosphite or borate and 
hydrogen ions as well as dissolved metal from the substrate are accumulating in the solution. The by-products will affect the deposition rate of the bath and increase slightly the phosphorus/boron content of the deposit. If the concentration of orthophosphite in the plating is increased, it will cause rough deposits and spontaneous decomposition of bath. Temperature, $\mathrm{pH}$, metal ion concentration and concentration of the reducing agent control the coating rate ${ }^{[35]}$.

\subsection{Electroless nickel}

Electroless nickel coating is most widely accepted in engineering application due to its unique characteristics, including excellent corrosion, wear and abrasion resistance, ductility, lubrication, soldering, and electrical properties. These coatings are more uniform in thickness than electroplated nickel coatings. The plating baths for electroless $\mathrm{Ni}$ are composed mainly of nickel sulfate (source of $\mathrm{Ni}$ ), sodium hypophosphate (reducing agent), and chemicals to prevent precipitation of insoluble nickel hydroxide. They are operated at about $85^{\circ} \mathrm{C}$ and $\mathrm{pH}$ is maintained in acid range for bath stability, but the generation of hydrogen lowers the $\mathrm{pH}$; to prevent this, alkaline salts of $\mathrm{Na}$ and $\mathrm{K}$ or ammonium ions are usually added. Fig. $4^{[36]}$ shows the effect of solution $\mathrm{pH}$ and bath temperature on the plating rate of electroless nickel deposits.

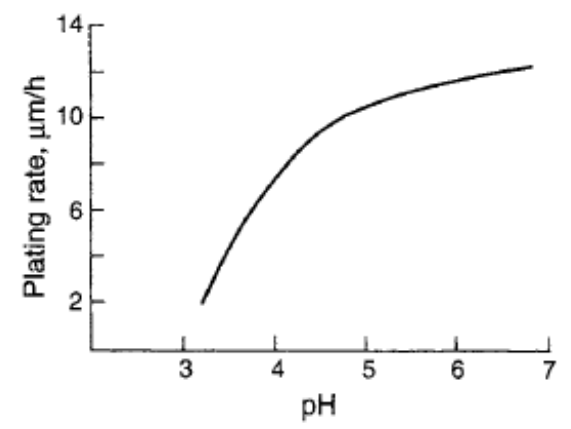

(a)

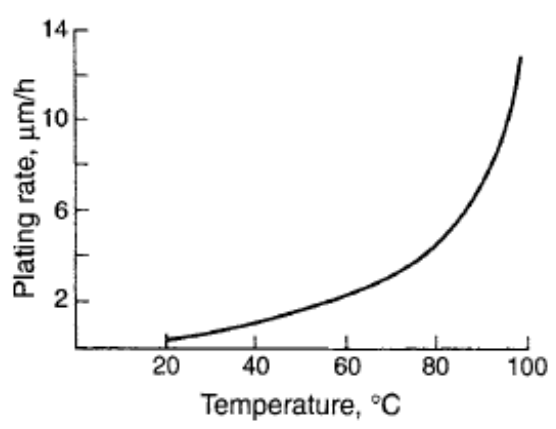

(b)

Fig. 4. Effect of solution $\mathrm{pH}$ and bath temperature on the plating rate of electroless nickel

$$
\text { deposits }{ }^{[36]} \text {. }
$$


Table 2: Typical components, operating conditions and applications of different electroless nickel coating baths

\begin{tabular}{|c|c|c|c|}
\hline Electroless bath & Pure nickel & Acid nickel-P/B & Alkaline nickel-P/B \\
\hline Temperature $\left({ }^{\circ} \mathrm{C}\right)$ & $85-90$ & $75-95$ & 25-95 \\
\hline Metal salts or source & Nickel acetate & Nickel sulfate, nickel chloride & Nickel sulfate, nickel chloride \\
\hline Reducing agents & Hydrazine & $\begin{array}{l}\text { Sodium hypophosphite, sodium } \\
\text { borohydride, dimethylamine (DMAB) }\end{array}$ & $\begin{array}{l}\text { Sodium hypophosphite, sodium borohydride, } \\
\text { dimethylamine (DMAB), hydrazine }\end{array}$ \\
\hline Complexing agents & $\begin{array}{l}\text { EDTA (tetra sodium } \\
\text { salt), glycolic acid }\end{array}$ & $\begin{array}{l}\text { Citric, lactic, glycolic, proprionic ionic } \\
\text { acids, sodium citrate, succinic acid }\end{array}$ & $\begin{array}{l}\text { Citric, lactic, glycolic, proprionic acids, sodium } \\
\text { citrate, sodium acetate, sodium pyrophosphate }\end{array}$ \\
\hline pH adjusters & & Sodium hydroxide, sulfuric acid & $\begin{array}{l}\text { Sodium hydroxide, sulfuric acid, ammonium } \\
\text { hydroxide }\end{array}$ \\
\hline
\end{tabular}


Hydrogen bubbles may attach to the substrate, during plating and hence, post-plating annealing may be needed to remove the hydrogen. Four reducing agents have been used for the industrial deposition of electroless nickel coatings. Sodium hypophosphite produces nickel-phosphorus alloys, which have a 90\% share of the industrial application. Sodium borohydride and amine boron produces nickel-boron alloys. Hydrazine produces pure nickel, which is over 99\% pure. Co-deposited phosphorus and boron must be controlled, because they lower the density and form amorphous alloy that interrupt the normal crystalline structure of the deposit. In contrast, an amorphous structure increases the corrosion resistance of the deposit. High phosphorus contents also decrease the magnetic properties associated with nickel, and the single largest application of high-phosphorus electroless nickel deposits is as under-layers beneath the magnetic coatings in memory disks. Further, the high phosphorus deposits exhibit low hardness and high wear, as the hardness of the deposit is inversely proportional to the phosphorus content in the deposit. However, high hardness can be regained in such deposits through a heat treatment at $300-400^{\circ} \mathrm{C}$, which converts Ni-P amorphous alloy into crystalline $\mathrm{Ni}$ and a hard nickel phosphide phase. This increases the hardness of the deposit (Fig. 5), but also decreases the corrosion resistance ${ }^{[37]}$. The degree of hardening depends on the content of phosphorus, heat treatment temperature, and time. Low temperature (nearly $350^{\circ} \mathrm{C}$ ) is needed to harden low phosphorus deposits $(\sim 3 \%)$ and high temperature (nearly $400^{\circ} \mathrm{C}$ ) is needed to harden high phosphorus alloys (10.5-12\%). Nickel boron alloy deposits can provide other additional properties uncommon with nickelphosphorus. Similarly, nickel-boron deposit characteristics change with boron content. Low B deposits are best suited for most applications. The properties of nickel-phosphorus/boron will be briefly reviewed in Section 4 . 


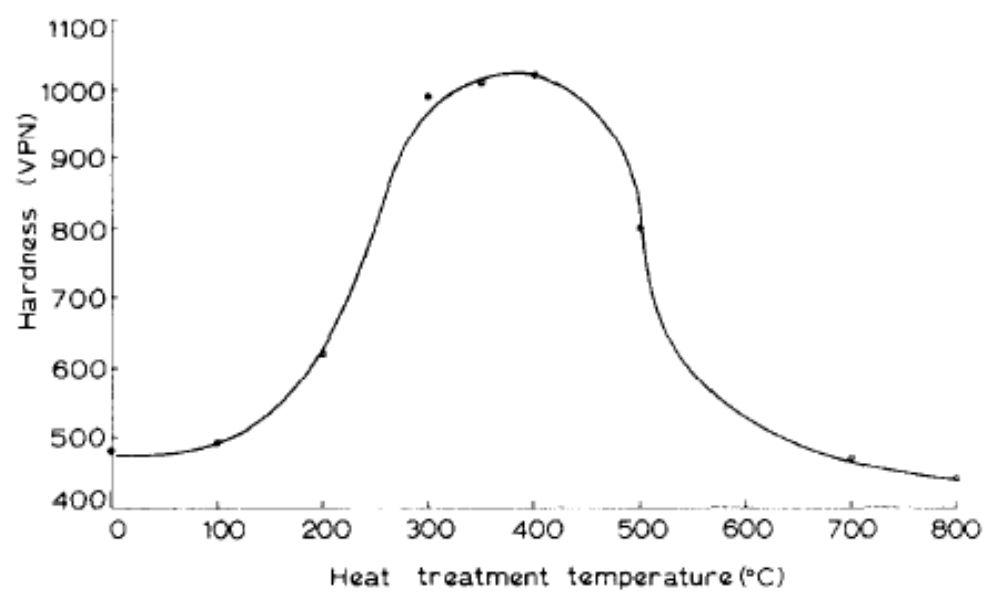

Fig. 5. Effect of heat treatment temperature on the hardness of nickel-phosphorus coatings, where it shows that heating at $400^{\circ} \mathrm{C}$ gives maximum hardness value ${ }^{[38]}$. The measurement of thickness is a most important test of electroless nickel coatings on their various substrates. Table 3 indicates the applicability of the coating thickness measuring methods. American Society for Testing and Materials (ASTM) and International Standards Organization (ISO) standards give thickness measurement methods ${ }^{[39]}$. The coulometric method is sensitive to variations in phosphorus content of the coating. The magnetic method is sensitive to permeability variations of the coating. The eddy current method is sensitive to both variations in phosphorus content of the coating, and permeability variations of the coating. 
Table 3: Thickness measurement methods of electroless nickel coating on various substrates

\begin{tabular}{ll}
\hline Substrate & Method \\
\hline Magnetic steel (including corrosion-resistant steel), glass & Coulometric, magnetic \\
sealing nickel-cobalt-iron alloys & \\
Non-magnetic stainless steels, copper and its alloys & Coulometric \\
Aluminum and its alloys & $\beta$ backscatter, coulometric, \\
& eddy current \\
Magnesium and its alloys, silver & $\beta$ backscatter \\
Non-metals & $\beta$ backscatter, coulometric \\
Titanium & $\beta$ backscatter, eddy current \\
\hline
\end{tabular}

Electroless nickel coatings may consist of four major types and as follows:

(1) Pure nickel and black nickel coatings

(2) Electroless nickel alloy coatings

Acid bath: Ni-P alloy, 3-5\% P (L), 6-9\% P (M), 10-14\% P (H)

Alkaline bath: Ni-P alloy

Acid bath: Ni-B alloy, 0.1-2\% B (L), 2-5\% B (M), 5-10\% B (H)

Alkaline bath: Ni-B alloy

Polyalloys

(3) Electroless composite coatings

(4) Electroless nanocoatings

\subsubsection{Pure nickel}

The phosphorus/boron alloy has been used with nickel, because of their different properties as compared to electrodeposited watts nickel. However, a 'pure' autocatalytic 
nickel would be of great use for certain applications such as semiconductor applications. This is usually reduced by hydrazine. Its typical bath composition is $60 \mathrm{~g} / \mathrm{l}$ nickel acetate, $60 \mathrm{~g} / \mathrm{l}$ glycolic acid, 25 g/l EDTA (tetra sodium salt), 100 g/l hydrazine and 30 g/l sodium hydroxide. The operating conditions are $\mathrm{pH} 10.5-11$, temperature $85-90^{\circ} \mathrm{C}$, giving a deposition rate of 6-12 $\mu \mathrm{m} / \mathrm{h}$. The hardness of as deposited pure nickel coating is $\sim 450 \mathrm{HV}$. After heat treatment at $450^{\circ} \mathrm{C}$ for $1 \mathrm{~h}$, the coating becomes much softer ( $125 \mathrm{HV}$ ) and much more ductile ${ }^{[40]}$.

This coating is restricted to little industrial interest, due to hydrazine cost and hazards. Electroless palladium and gold bath having hydrazine as a reducing agent have also been reported $^{[41]}$.

\subsubsection{Black nickel}

It can be obtained from the surface of both electro and electroless deposition by etching the surface using oxidizing acid solutions ${ }^{[42]}$. Due to the presence of phosphorus contents, the electroless nickel deposit is easy to etch by the oxidizing acids to get the ultra black surface. The blackening of electroless nickel deposit is obtained, when the deposit is dipped in a nitric acid $(9 \mathrm{M})$ solution. The blackening resulting from the hole formation is visible first on the boundaries between the different nodules and then on the whole deposit surface on titanium alloy (see SEM image in Fig. 6) ${ }^{[43]}$. This structure produced by selective etching traps the light and is capable of absorbing over 99\% light in solar region $(0.3-2 \mu \mathrm{m})$ [44]. Moreover, these surfaces are extremely suitable in improving the absorption of thermal detectors and to minimize the effect of stray and scattered light in optical instruments and sensors. The optimum thickness of $35 \pm 5 \mu \mathrm{m}$ of electroless nickel is required to achieve the ultra high optical properties for blackening. Electroless nickel coatings with $\sim 7 \%$ phosphorus are good for further blackening. Higher phosphorus content alloys are not suitable, because 
they are too corrosion resistant to blacken as a result of acid etching ${ }^{[45]}$. The main components of the black coating are recognized to include $\mathrm{NiO}, \mathrm{Ni}_{2} \mathrm{O}_{3}$ and some nickel phosphate ${ }^{[46]}$. The blackened electroless nickel provides higher optical properties in the order of $\sim 0.85 \alpha_{\mathrm{s}}$ (solar absorbance); this coating has good adhesion, uniformity, and stability in adverse space conditions. Hence, it is widely used in solar absorber for solar applications ${ }^{[43]}$.

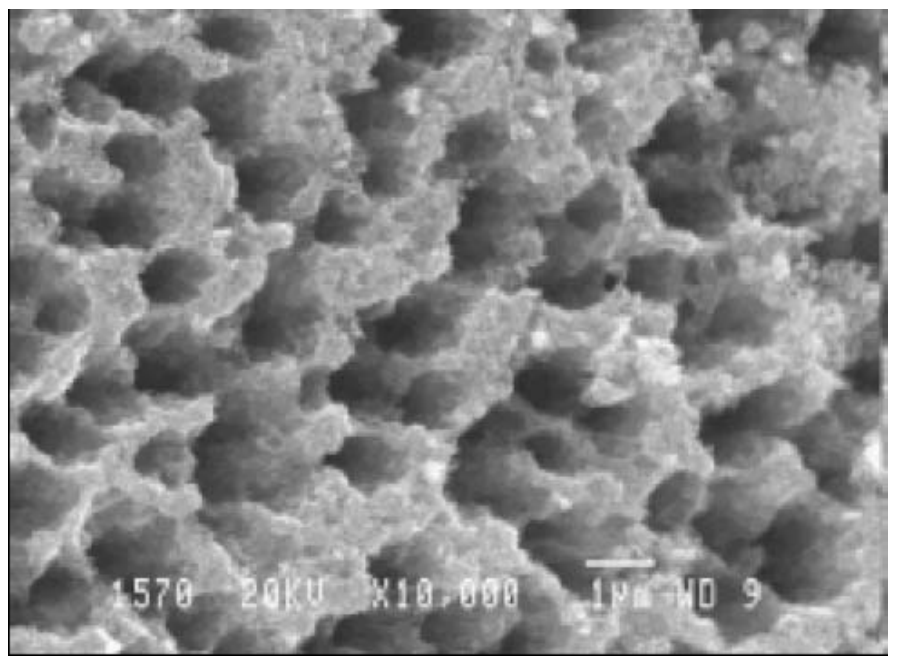

Fig. 6. SEM image of black electroless nickel coating with $\sim 7 \% \mathrm{P}$ content on titanium alloy for spacecraft thermal control applications ${ }^{[43]}$.

\section{Electroless nickel alloy coating}

\subsection{Acid bath Ni-P alloy}

The hot acid solutions were found to have several advantages over alkaline solutions. Hot acid electroless nickel baths are used almost exclusively for the deposition of relatively thick coatings onto metals. The coatings obtained from the acid solution are of better quality and the bath solution is more stable during plating. Thermal stability upon heating (crystallisation) should not depend on solution, however. The phosphorus content can be controlled easily in due respect of their properties. They can be sub-classified into: 
(i) 3-5\% P (low phosphorus). These coatings have excellent wear resistance. They have excellent corrosion resistance in concentrated caustic soda.

(ii) 6-9\% P (medium phosphorus). Corrosion protection and abrasion resistance are good enough for most applications. The plating bath works economically.

(iii)10-14\% P (high phosphorus). The coatings are very ductile and corrosion resistant. Particularly, they have corrosion resistance against chlorides and simultaneous mechanical stress ${ }^{[35]}$.

A typical bath composition is $33 \mathrm{~g} / \mathrm{l}$ nickel sulfate, $20 \mathrm{~g} / \mathrm{l}$ sodium hypophosphite, 28 g/l lactic acid, $16 \mathrm{~g} / \mathrm{l}$ sodium succinate, and $0.003 \mathrm{~g} / \mathrm{l}$ lead $\left(\mathrm{Pb}^{2+}\right)$. Operating conditions are $\mathrm{pH}$ 5-6, temperature $85-95^{\circ} \mathrm{C}$, giving a deposition rate of $25 \mu \mathrm{m} / \mathrm{h}$.

\subsection{Alkaline bath Ni-P alloy}

Hot alkaline nickel-phosphorus deposits are generally reduced by sodium hypophosphite. A typical bath composition is $30 \mathrm{~g} / \mathrm{l}$ nickel chloride, $10 \mathrm{~g} / \mathrm{l}$ sodium hypophosphite, $65 \mathrm{~g} / \mathrm{l}$ ammonium citrate, and $50 \mathrm{~g} / \mathrm{l}$ ammonium chloride. Operating conditions are $\mathrm{pH} 8-10$, temperature $80-90^{\circ} \mathrm{C}$, giving a deposition rate of $10 \mu \mathrm{m} / \mathrm{h}$. The main disadvantage of the alkaline solution is its high instability at temperature above $90^{\circ} \mathrm{C}$, where bath $\mathrm{pH}$ suddenly decreases due to loss of ammonia. As a main advantage, the alkaline low temperature bath is a convenient way to deposit nickel on plastics. A typical bath composition is $20 \mathrm{~g} / \mathrm{l}$ nickel chloride, $24 \mathrm{~g} / \mathrm{l}$ sodium hypophosphite, $45 \mathrm{~g} / \mathrm{l}$ sodium citrate, and $30 \mathrm{~g} / \mathrm{l}$ ammonium chloride. Operating conditions are $\mathrm{pH}$ 8-9, temperature $30-40^{\circ} \mathrm{C}$, giving a deposition rate of $8 \mu \mathrm{m} / \mathrm{h}$. Deposits provide good solderability for the electronic industry. However, lower corrosion resistance, lower adhesion to steel and difficulty in processing aluminum due to high $\mathrm{pH}$ values are the limitations.

The rate of deposition is very much temperature-dependent and so the alkaline bath found little industrial use for deposition of thick coatings. The hot acid hypophosphite- 
reduced baths are most frequently used to plate steel and other metals, whereas warm alkaline hypophosphite baths are used for plating plastics and non-metals ${ }^{[14]}$.

The sudden bath decomposition is the major problem in electroless nickel deposition, which results in an increase in the operating cost of the process and the generation of environmentally hazardous waste. Bath stabilizers have normally been added to extend its life. Sodium benzene sulfonate as an organic additive was found to cause brightening and have stabilizing effects as well as producing a good deposition rate and superior adhesion deposit ${ }^{[47]}$. Yin et al. developed a theoretical model for understanding this complicated electroless deposition system from the role of heavy metal $\mathrm{Pb}^{2+}$ ion stabilizers ${ }^{[48]}$. The structure of the Stern-Grahame electrical double layer and the electronic tunneling theory of the quantum mechanics were applied for explaining the electroless nickel plating mechanism and stability of the bath. Xiao et al. ${ }^{[49]}$ studied the addition of $\mathrm{Cd}^{2+}$ as a stabilizer. It increases the stability of the electroless nickel plating bath significantly, although it had negligible effect on the plating rate and $\mathrm{P}$ content of the Ni-P deposits within low concentration ranges. In other studies ${ }^{[50-51]}$, the addition of thiourea and maleic acid significantly improves the stability of the electroless nickel bath. In addition, it has an effect on the nano grain size of the electroless nickel deposits and thereby it increases the corrosion resistance ${ }^{[52]}$. An addition of small amount of surfactants to the plating bath increases the deposition rate by $25 \%$ compared to that from the surfactant-free bath ${ }^{[53]}$. Ashassi-Sorkhabi et al. studied the effects of added rare earth elements in the acidic hypophosphite based electroless nickel-phosphorus plating bath ${ }^{[54]}$. An addition of optimum amounts of rare earth elements to the plating baths could increase the deposition rate in comparison with the rare earth-free bath and refine the microstructure of the deposit and produce smooth and mirror-like coatings.

A novel process of non-isothermal deposition coating system can be used to coat the electroless nickel under the substrate working temperature as high as $180^{\circ} \mathrm{C}$ and gives an 
increased deposition rate without deteriorating the electrolyte and auto-accelerating the decomposition of bath as well. As substrate temperature increases, the deposition rate increases. However, the effect of bath temperature cannot be ignored. When the bath temperature is high, plating bath is destroyed seriously by the Cannizzaro reaction. This nonisothermal method allows deposition rates to increase at certain conditions, than conventional isothermal method ${ }^{[55]}$. Srinivasan and John formulated a new electroless bath using the nickel methane-sulfonate as the source of metal ions. The absence of sulfate ions increases the bath life of the electroless nickel bath solution. The small amount of nickel sulfonate is needed for replenishments due to higher solubility of the nickel sulfonate. The methane sulfonate anions increases in the concentration with age of the bath. The addition of calcium to the aged solution allows for the selective removal of orthophosphite thus increasing electroless nickel bath life ${ }^{[56]}$.

Monir Vaghefi and Monir Vaghefi developed a multilayer feed forward neural network model with two hidden layers for the prediction of the phosphorus content of electroless Ni-P deposits ${ }^{[57]}$. This model can be used for adjusting the phosphorus content of electroless Ni-P deposits in a variety of industries and the same group also modeled a process for adjusting the hardness of electroless Ni-P deposits ${ }^{[58]}$. The newer developments in the polyalloy and composite Ni-P coatings will be reviewed in Sections 3.5 and 5, respectively.

\subsection{Acid bath Ni-B alloy}

DMAB is usually used as a reducing agent in acid bath for electroless nickel-boron coatings where boron contents vary from 0.1 to $4 \%{ }^{[59]}$. The main advantage of the hot acid bath is its stability and deposits from this bath have a very high melting point of $\sim 1,350^{\circ} \mathrm{C}$. They are very often used in industrial wear applications for their as-plated hardness, which is higher than that of nickel-phosphorus. They have good soldering, brazing and ultrasonic 
bonding characteristics, when boron is $>1 \%$. Boron can be usually reduced by alkyl amine, although up to $5 \%$ can be obtained by using some accelerator. A typical bath composition is 30 g/l nickel chloride, 3 g/l diethylamine borane, 40 g/l methanol, 4 g/l dimethylamine borane (DMAB), 20 g/l sodium acetate, 20 g/l sodium succinate, and 10 g/l sodium citrate. Operating conditions are $\mathrm{pH} 5-6$, temperature $50-60^{\circ} \mathrm{C}$, giving a deposition rate of $15-20 \mu \mathrm{m} / \mathrm{h}$.

\subsection{Alkaline bath Ni-B alloy}

The boron contents of the alkaline electroless nickel-boron deposit range from 0.2 to 4 wt.\% and from 4 to 7 wt.\% when the reducing agents are aminoborane ( $\mathrm{N}$-alkyl amino boranes) and sodium borohydride, respectively. They are usually operated at temperature in the range of $20-90^{\circ} \mathrm{C}$. Alkaline Ni-B cool bath has been preferred. At high temperature, bath becomes unstable and has limited industrial usage. These alkylamine borane baths generally have a much slower deposition rate. Complexing agents such as ethylendiamine are used to control nickel hydroxide precipitation ${ }^{[60]}$. A typical alkaline hot bath composition is $30 \mathrm{~g} / \mathrm{l}$ nickel chloride, $60 \mathrm{~g} / \mathrm{l}$ ethylenediamine, $1.2 \mathrm{~g} / \mathrm{l}$ sodium borohydride, $0.07 \mathrm{~g} / \mathrm{l}$ thallium nitrate, and $40 \mathrm{~g} / \mathrm{l}$ sodium hydroxide. Operating conditions are $\mathrm{pH} 14$, temperature $90^{\circ} \mathrm{C}$, giving a deposition rate of $20-25 \mu \mathrm{m} / \mathrm{h}$. A typical alkaline cool bath composition is $30 \mathrm{~g} / \mathrm{l}$ nickel sulfate, 3 g/l dimethylamine borane (DMAB), 15 g/l ammonium citrate, 15 g/l ammonium chloride, and $0.0002 \mathrm{~g} / \mathrm{l}$ 2-metcaptobenzothiazole. Operating conditions are $\mathrm{pH} \geq 7.5$, temperature $25-35^{\circ} \mathrm{C}$, giving a deposition rate of $7-12 \mu \mathrm{m} / \mathrm{h}$.

The main advantages of borohydride reduced electroless nickel deposits are their hardness and superior wear resistance in the as-deposited condition. Dervos et al. proposed a vacuum heating technique within less than half an hour and leading to surface hardness values normally requiring processes of several months by the conventional approaches, i.e. heating in an inert atmosphere ${ }^{[61]}$. The 5 min thermal treatment in a high vacuum 
environment results in a chromium equivalent surface microhardness, which in some cases reaches $2000 \mathrm{HV}$ locally, without the environmental hazardous sewages of the hard chromium plating. The method can be used for a variety of industries, where they need to replace hard chromium plating. Kanta et al. investigated electroless Ni-B on mild steel with different post-treatments, including heat-treatments in $95 \% \mathrm{Ar}$ and $5 \% \mathrm{H}_{2}$ at $400^{\circ} \mathrm{C}$ for $1 \mathrm{~h}$, and thermo-chemical treatments. The thermo-chemical treatment was performed in a nitrogen based atmosphere, at $500^{\circ} \mathrm{C}$ for $2 \mathrm{~h}$, followed by a treatment based on ammonia. After heat and thermo-chemical treatments, Ni-B coatings crystallize and produce nickel and nickel borides in the coatings ${ }^{[62]}$. The same authors prepared the Ni-P and Ni-B system onto, respectively, steel substrate and specially prepared aluminum substrate that were protected by an outer layer of Ni-P deposit, and found smoother surface, more noble electrochemical comportment than the Ni-B ${ }^{[63]}$. Further, nanocrystalline electroless nickel-boron deposits were synthesized on mild steel substrates to enhance wear and mechanical properties of the deposits ${ }^{[64]}$. The newer developments in polyalloy and composite nickel boron coatings will be reviewed in Sections 3.5 and 5, respectively.

\subsection{Polyalloys}

The electroless method is one of the elegant processes to deposit alloy coatings. Ternary and quaternary alloys are referred to in literature as polyalloys ${ }^{[65]}$. Some alloys of Ni-Co-P, Ni-Fe-P and Ni-Co-Fe-P have been widely used because of their superior magnetic properties. High-coercivity films have been adopted for high-density recording, whereas lowcoactivity alloys have been suggested for high-speed computers. A ternary alloy Ni-Cu-P (1 at.\% $\mathrm{Cu}$ ) has high corrosion resistance and high ductility as compared with standard Ni-P

alloy ${ }^{[66-67]}$. Ternary alloy containing molybdenum (Ni-Mo-B) has good solderability (17 at.\% Mo, 0.3 at.\% B) and its non-ferromagnetism makes it particularly useful in electronics industry. Ternary alloys having tungsten (10 at.\% W) provide an increase in hardness and 
corrosion resistance and alloy having up to $40 \%$ tin (Sn) are considered as good corrosion resistant materials. Generally, polyalloys find applications where unique chemical and high temperature resistance or electrical, magnetic or non-magnetic properties are required. Different alloys are coated for desired physical and mechanical applications, and the selection of the alloy depends upon the applications and economic considerations. Electroless deposited alloy features and types of metallic non-electrolytic alloy coatings are summarized in Table 4.

Table 4: Features and types of electroless metallic alloy coatings

\begin{tabular}{ll}
\hline Use & Alloy types \\
\hline Corrosion protection & Ni-P, Ni-P-Mo, Ni-Sn-P, Co-P, Co-P-Mo, Ni-Cu-P \\
Wear resistance & Ni-B, Ni-B-Tl, Ni-B-Mo, Ni-B-Sn, Co-P, Co-P-W, Co-B; Ni-P-SiC, \\
& Ni-P-WC (dispersion) \\
Magnetic & Au-Ni, Au-Co; Ni-Co-P, Ni-Co-B, Ni-Fe-P \\
Solderability & Sn-Pb, Ni-P \\
High temperature & Co-W-B, Ni-Re-P \\
Diffusion barrier & Ni-P \\
\hline
\end{tabular}

The third element co-deposition in electroless Ni-P plating influences the coatings properties. The inclusion of $\mathrm{Cu}$ or $\mathrm{Sn}$ in electroless $\mathrm{Ni}-\mathrm{P}$ increases the thermal stability of amorphous state, ensures the preservation of a paramagnetic behavior and improves the corrosion resistance ${ }^{[68]}$. When the Cu content in the coatings is $17.2 \mathrm{wt} . \%$, the anti-corrosion performance of the Ni-Cu-P deposits is the best ${ }^{[69]}$. The addition of $\mathrm{Cu}$ in the $\mathrm{Ni}-\mathrm{Cu}-\mathrm{P}$ system accelerates the selective dissolution of $\mathrm{Ni}$, resulting in the enrichment of $\mathrm{P}$ and $\mathrm{Cu}$ elements in the surface layer of the coating. The passivation layer inhibits the dissolution of 
$\mathrm{Ni}$ and the diffusion of $\mathrm{Ni}^{2+}$ toward the bulk solution, thereby increasing the corrosion resistance of Ni-Cu-P coating. This coating is used not only for the practical flue gas condensation, but also for the potential application in heat exchanger ${ }^{[70]}$. In addition, the hybrid multilayered deposits on mild steel, Ni-Cu-P/Ti/TiN have improved mechanical behavior in terms of friction coefficient and nano-hardness in comparison with just Ni-Cu-P on mild steel. Hence, this type of the hybrid multilayered coatings could have high prospective for simultaneous improvement of corrosion resistance and mechanical properties [71].

The addition of Sn (1-2 wt.\%) or Cu (3-4 wt.\%) to high phosphorus ( $\geq 10$ wt.\% P) coatings increases the crystallization temperature of the amorphous electroless Ni-P deposits. Yuan et al. ${ }^{[72]}$ succeeded in fabricating large-scale and uniform electroless Ni-W-P alloy nanowire arrays in an anodic alumina membrane for the purpose of ultra-high-density magnetic recording. In addition, the addition of tungsten into Ni-P coating effectively enhanced the thermal stability and mechanical properties. Addition of copper or tin in Ni-W$\mathrm{P}$ baths has resulted in quaternary deposits Ni-W-Cu-P and Ni-W-Sn-P with increased crystallinity ${ }^{[73-75]}$. The electroless Ni-W-P coating system can be used as a potential material that protects a storage container from corrosive attacks by biodiesel ${ }^{[76]}$. In another study, the laser surface treatment on $\mathrm{Ni}-\mathrm{W}-\mathrm{P}$ system produced nanocrystalline $\mathrm{Ni}$ phase and $\mathrm{Ni}_{3} \mathrm{P}$ precipitation with remaining amorphous structure. Corrosion performance of the deposits was greatly enhanced by the laser surface treatment. The porosity, integrated intensity ratios of individual phases, grain sizes of phases, microstrain and residual stress were also considered. The selection of laser parameters depends on coating thickness, alloy properties and so on ${ }^{[77]}$. Wang ${ }^{[78]}$ deposited electroless Ni-Fe-P alloys by using boric acid as a buffer agent and sodium citrate as a complexing agent. It was found that the presence of ferrous sulfate in the bath has an inhibitory effect on the deposition of the alloy. The percentage of iron in the 
deposits never reaches high values. Indeed, it was observed to be less than 15.6 at.\%. The mechanical properties of the coatings are improved, as the Fe content increases and the P content decreases. The ternary electroless Ni-Zn-P alloy coating was used as a new type of the under-bump metallization (UBM) to react with Pb-free solder and Ni-8Zn-8P coating film exhibited better thermal stability than that of Ni-P coating film. This new ternary Ni-Zn-P film may be one alternative for conventionally used $\mathrm{Ni}-\mathrm{P}$ or $\mathrm{Au} / \mathrm{NiP}$ film for $\mathrm{UBM}$ application ${ }^{[79]}$. Duhin et al. proposed a novel method to develop the NiSi contacts by electroless plating of Ni-alloys (Ni-P, Ni-W-P, Ni-W-B) on p-type Si(100), using aminopropyltriethoxysilane (APTS) activated with Pd citrate. The Ni electroless plating can be applied for the development of NiSi thin layers. The electroless deposition and the associated silanization by APTS activation processes can be from the liquid phase. This process is relatively simple and do not require sophisticated vacuum deposition system. As a result, it offers a simpler and lower cost process when compared to evaporation and sputtering technique. Nevertheless, further optimization is needed to obtain layers with enhanced properties ${ }^{[80]}$.

Pang et al. prepared a pre-treatment process for electroless Ni-Co-P coating on fly ash cenospheres (FACs) by using $\gamma$-aminopropyltriethoxy silane (APTES), which enhanced the continuity and uniformity of the alloy coatings considerably. The deposition rate depends on the mole ratios of $\mathrm{NiSO}_{4} / \mathrm{CoSO}_{4}$, the sodium hypophosphite concentration and $\mathrm{pH}$ of the plating bath and it was found that the plating rate of electroless Ni-Co-P deposits rose as mole ratio of $\mathrm{Ni}^{2+} / \mathrm{Co}^{2+}$ increases. The increase of $\mathrm{NaH}_{2} \mathrm{PO}_{2}$ concentration and $\mathrm{pH}$ could also raise the plating rate of deposits. The as-deposited Ni-Co-P amorphous phase transformed to crystal phases with increase in sintering temperature. In addition, the soft magnetic properties of the composite got better as the cobalt content of the deposits and calcining temperature increased ${ }^{[81]}$. A new method has been developed to reduce core loss in commercial Fe-3\%Si 
electrical steel by electroless plating. This method involves electroless plating of magnetic thin film onto the surface of electrical steel. The film was amorphous and composed of 56-59\% Ni, 32-35\% Co, and $8-10 \% \mathrm{P}$ by mass value. It is possible to reduce core loss of electrical steel by applying electroless Ni-Co-P coating. A core loss reduction was obtained with the Ni-Co-P of $1 \mu \mathrm{m}$ thickness magnetized at $0.3 \mathrm{~T}$ (magnetic flux density) ${ }^{[82]}$. The new progress in polyalloy with composite coating will be reviewed in Section 5.

\section{Ni-P and Ni-B properties}

The electroless nickel deposition is an elegant method to produce varying composition of phosphorus/boron alloy. Depending on the formulation and the operation chemistry, film compositions can vary from 2 to 14 wt.\% for phosphorus, and 0.1 to $10 \mathrm{wt} \%$ for boron. This variation in alloy content has significant advantages. As deposited, nickelphosphorus coatings are uniform, hard, relatively brittle, lubricous, easily solderable and highly corrosion resistant. This combination of properties makes the coatings well suited for many severe applications and often allows them to be used in place of more expensive or less readily available alloys. The properties of $\mathrm{Ni}-\mathrm{B}$ are mostly similar to that of $\mathrm{Ni}-\mathrm{P}$ with a few differences. The hardness of heat treated Ni-B alloy is very high compared with hard chromium. It has excellent resistance to wear and abrasion. Ni-B film is more costly than NiP but with reduced corrosion resistance. Typical physical and mechanical properties of electroless Ni-P/B coatings are summarized in Table $5^{[26]}$. 
Table 5: Typical physical and mechanical properties of electroless Ni-P/B coatings

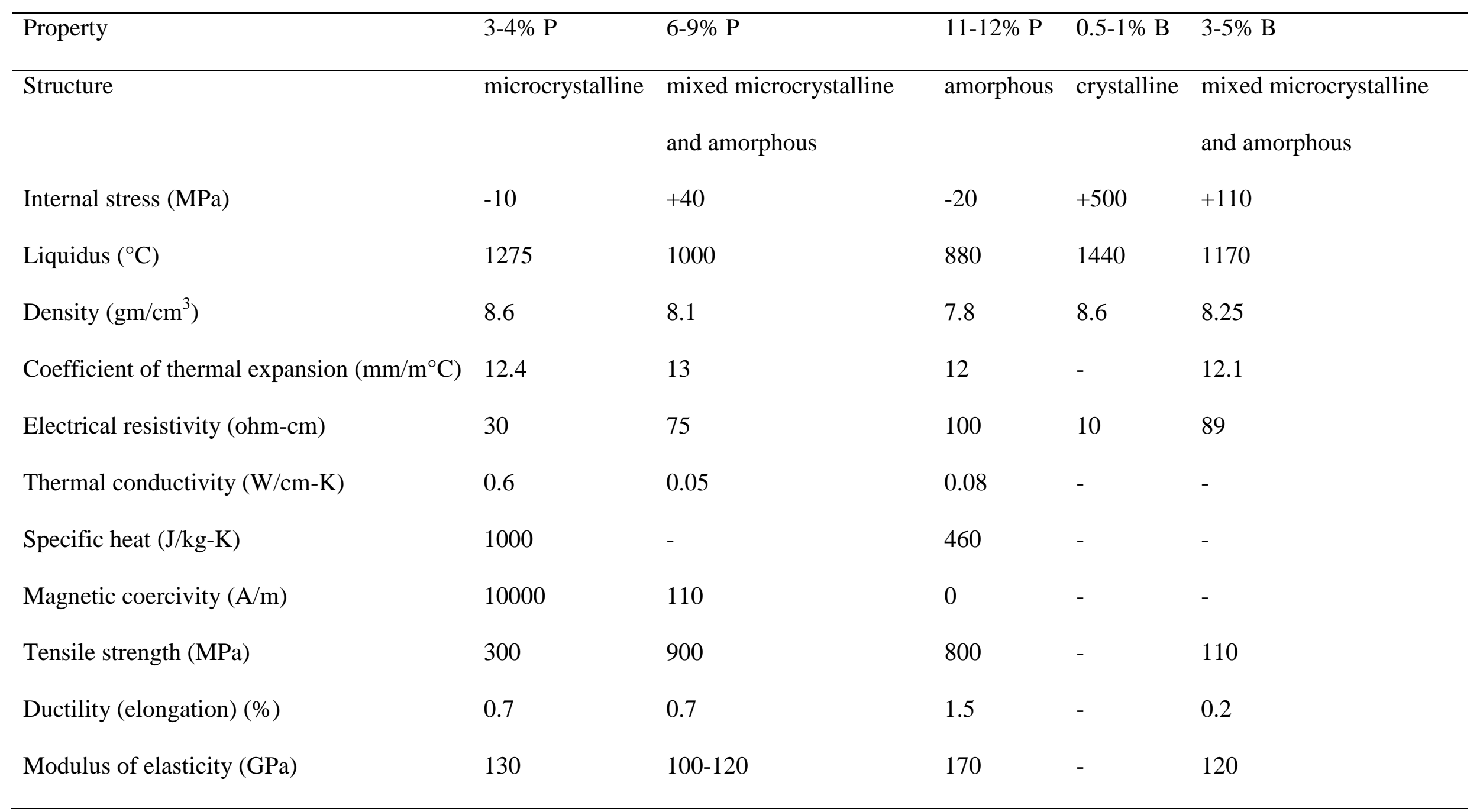




\subsection{Physical properties}

\subsubsection{Deposit uniformity}

This is an important physical property and a significant advantage of the electroless nickel process. It is the ability to produce uniform thickness on parts with complex geometries and shapes [26, 83$]$. The current density effect typically associated with electroplating is not a factor here; therefore sharp edges, deep recesses and blind holes are readily plated to have uniform thickness with electroless nickel process. Electrodeposition leads to the excessive buildup at projections, edges and finish-grinding operation may be required. Electroless deposits avoid these drawbacks.

\subsubsection{Structure}

The coatings are a mixture of amorphous and microcrystalline nickel at low and medium phosphorus level, but it is fully amorphous when the phosphorus content is high. The final products of the deposits after heating to $800^{\circ} \mathrm{C}$ are all mixtures of $\mathrm{Ni}_{3} \mathrm{P}$ and f.c.c. nickel stable phase ${ }^{[37,84]}$. Intermediate metastable phases such as $\mathrm{NiP}_{2}$ and $\mathrm{Ni}_{12} \mathrm{P}_{5}$ may form with medium and high phosphorus contents before formation of stable $\mathrm{Ni}_{3} \mathrm{P}$ phase. $\mathrm{Ni}-\mathrm{P}$ begins to change its structure at temperature above 220 to $260^{\circ} \mathrm{C}$, and the deposit begins to crystallize and lose its amorphous structure. Nickel phosphite $\left(\mathrm{Ni}_{3} \mathrm{P}\right)$ first forms within the alloy when temperature rises above $320^{\circ} \mathrm{C}$. It reaches maximum crystallized structure after heating at temperature $400^{\circ} \mathrm{C}$ for $1 \mathrm{~h}$, where we expect high corrosion resistance, hardness and wear resistance. In coating with more than $9 \%$ phosphorus, a matrix of nickel phosphite $\left(\mathrm{Ni}_{3} \mathrm{P}\right)$ forms whereas almost pure nickel is the dominant phase in deposits with lower phosphorus content. To avoid the blue color in the heat-treated samples, that is due to oxide layer combined with air, one must keep them in vacuum furnace. Heat-treated sample will give 
higher hardness and wear resistance but reduced corrosion resistance. In Ni-B, commercial coating contains $5 \%$ boron ${ }^{[85]}$ and unlike Ni-P, Ni-B has crystalline nickel mixed with nickel-boron $\left(\mathrm{Ni}_{2} \mathrm{~B}\right)$ glass structure. These coatings contain mixed crystalline and amorphous structure. Like Ni-P, Ni-B also starts crystallization above $250^{\circ} \mathrm{C}{ }^{[83,86]}$ where particles of nickel boride $\left(\mathrm{Ni}_{3} \mathrm{~B}\right)$ form and at 370 to $380^{\circ} \mathrm{C}$, the coating crystallizes. Finally, Ni-B consists of intermetallic compounds (mainly, $\mathrm{Ni}_{3} \mathrm{~B}$ and $\mathrm{Ni}_{2} \mathrm{~B}$ ).

\subsubsection{Density}

The density of electroless Ni-P and Ni-B is similar to that of equal alloy content. This is inversely proportional to their phosphorus/boron content ${ }^{[85-86]}$. The density varies in the range of $8.5 \mathrm{gm} / \mathrm{cm}^{3}$ (low P) to $7.75 \mathrm{gm} / \mathrm{cm}^{3}$ (high P), whereas $8.25 \mathrm{gm} / \mathrm{cm}^{3}$ for $5 \%$ B.

\subsubsection{Melting point}

The electroless Ni-P deposits do not have a precise melting point but rather have a melting range unlike electrolytically deposited nickel. Pure nickel has a melting point of $1455^{\circ} \mathrm{C}$ but as the phosphorus content increases, the deposit begins to soften at lower temperatures ${ }^{[83]}$. Electroless Ni-P deposits containing 11\% P have a lowest melting point of $880^{\circ} \mathrm{C}$. Low phosphorus deposits (less than 3\%) have highest melting points, around 1200 ${ }^{\circ} \mathrm{C}$. The melting point of Ni-B is relatively high. Sodium borohydride reduced electroless NiB deposits containing $5 \% \mathrm{~B}$ have melting point at $1080^{\circ} \mathrm{C}$, while melting point is about 1350 to $1360^{\circ} \mathrm{C}$ in $\mathrm{DMAB}$ reduced bath.

\subsubsection{Electrical resistivity}

The electrical resistivity of electroless nickel alloys is higher than that of pure nickel [x]. Pure nickel has a specific resistivity of $7.8 \times 10^{-6} \mathrm{ohm}-\mathrm{cm}$. When phosphorus content increases, the electrically resistivity also increases and, depending on depositing condition, 
ranges $30-100 \times 10^{-6} \mathrm{ohm}-\mathrm{cm}$. Heat treatment on electroless Ni-P can increase its conductivity and affect the resistivity. The electrical resistivity of $9 \% \mathrm{P}$ is $89 \times 10^{-6} \mathrm{ohm}-\mathrm{cm}$ in the as deposited conditions and $43 \times 10^{-6} \mathrm{ohm}-\mathrm{cm}$ after heat treatment at $1100^{\circ} \mathrm{C}$. The electrical resistivity property of $\mathrm{Ni}-\mathrm{B}$ is similar to that of $\mathrm{Ni}-\mathrm{P}$. It has a value of $89 \times 10^{-6} \mathrm{ohm}-\mathrm{cm}$ for 5\% B. Major applications of Ni-B are in electronic industries in low resistivity field.

\subsubsection{Magnetic property}

The single largest application for electroless nickel is as a sub layer for computer memory disk. In order to fulfill the requirements for this application, it should remain nonmagnetic even after one-hour bake cycles of $250-320^{\circ} \mathrm{C}$. More than once baking is the requirement. The non-magnetic property of this high phosphorus coating is the most important physical characteristic; this could be achieved only with high phosphorus $(>10.5$ wt.\% P). Microcrystalline and maintaining homogeneous grain sizes at higher bake temperature are key requirements for optimal thermo-magnetic properties of the coatings ${ }^{[\mathrm{x}]}$. Nickel-phosphorus has non-magnetic property, whereas nickel-boron is very weakly ferromagnetic in nature. Electroless nickel that has a high enough phosphorus content $(\geq 7$ wt.\%) is amorphous and therefore non-magnetic, and is commonly used as an under layer for magnetic coatings. These storage systems represent a demanding tribological environment, because of the need to maintain minimal separation between the read/write heads and the storage media.

\subsection{Mechanical properties}

The mechanical properties mainly depend on the phosphorus/boron content in the deposit. The coatings normally have high strength, limited ductility, and high modulus of elasticity. The ultimate tensile strength of commercial coatings exceeds $700 \mathrm{MPa}$ and allows the coatings to withstand loading without damage ${ }^{[87]}$. 


\subsubsection{Internal stress}

Internal stress in the electroless nickel coatings is main function of coating composition. With lower phosphorus deposits, tensile stresses of 15 to 45 MPa develop, because of the difference in thermal expansion between the deposits and the substrate. The high level of stress in these coatings promotes cracking and porosity. The structural changes during heat treatment at temperatures above $220^{\circ} \mathrm{C}$ cause a volumetric shrinkage of electroless nickel deposits of up to $6 \%$. This increases tensile stress and reduces compressive stress in the coating. Deposit stress can also be increased by the co-deposition of orthophosphites or heavy metals, as well as by the presence of excess complexing agents in the plating solution. Even small quantities of some metals can produce a severe increase in stress. High levels of internal stress also reduce the ductility of the coating ${ }^{[83]}$.

\subsubsection{Ductility}

Ductility of the electroless Ni-P coating also varies with composition. The codeposition of composites will affect the ductility properties. For deposits in as-deposited condition with relatively high phosphorus content, coatings have a ductility of 1 to $1.5 \%$ (as elongation). Although this is less ductile than most engineering materials, it is adequate for most coating applications. Thin films of deposit can be bent completely around themselves without fracture. With low phosphorus, however, the ductility is greatly reduced and may approach zero ${ }^{[14]}$. The ductility of the electroless Ni-B is one fifth (0.2\%) of high phosphorus deposits. However, heat treatment has little effect on the ductility.

\subsubsection{Tensile strength}

The tensile strength value of Ni-P deposits is higher than that of Ni-B deposits. In asdeposited condition, low phosphorus deposit has the value of 450-550 MPa. Heat treated Ni- 
P possesses lower tensile strength than that of as-deposited one but its hardness increases ${ }^{[14]}$. Its value is found to be $200-300 \mathrm{MPa}$.

\subsubsection{Hardness}

As-deposited hardness of electroless Ni-P and Ni-B coatings (Table 6) is equivalent to many hardened alloy steels. This is in contrast to as-deposited electrolytically deposited nickel, which has typical values of 150 to $400 \mathrm{HV}_{0.1}{ }^{[88]}$. EN can be heat treated to hardness comparable to those of electrodeposited chromium. The maximum hardness can be attained in $1 \mathrm{~h}$ at about $400^{\circ} \mathrm{C}$ or $10 \mathrm{~h}$ at $260^{\circ} \mathrm{C}$. The ability of electroless nickel deposits to maintain their hardness under elevated-temperature service conditions increases with increasing phosphorus or boron content, but decreases rapidly above $385^{\circ} \mathrm{C}$. Ni-B coatings tend to better withstand wear at elevated temperatures and are therefore more widely used under these conditions. Hardness of electroless nickel coatings in as-deposit and heat-treated conditions in respect of phosphorus/boron content is compared in Table $6^{[26]}$. Yan et al. developed a high hardness value of $910 \mathrm{HV}_{0.1}$ of as-deposited Ni-P coating at 8 at.\% phosphorus content, by varying the ratio of lactic acid to acetic acid in the electroless bath, and high wear resistance was accordingly achieved ${ }^{[89]}$.

Table 6: Hardness $\left(\mathrm{HV}_{0.1}\right)$ of electroless nickel coatings

\begin{tabular}{lll}
\hline Phosphorus/boron content & As-deposited & Heat-treated $\left(400^{\circ} \mathrm{C} / \mathrm{h}\right)$ \\
\hline $2-3 \%$ P & 650 & 1200 \\
$6-9 \%$ P & 620 & 1100 \\
$10-12 \%$ P & 520 & 1050 \\
$1-5 \%$ B & 700 & 1280 \\
$5-10 \%$ B & 570 & 1120 \\
\hline
\end{tabular}




\subsubsection{Solderability}

Electroless nickel-phosphorus can be easily soldered compared to boron deposits. It is used in electronic application to facilitate soldering such light metals as aluminum. Rosin mildly activated (RMA) flux along with conventional Sn-Pd solder is most common. Pretemperature of the component around $100^{\circ} \mathrm{C}$ improves the ease and speed of joining and this flux is just for wetting the coating surface ${ }^{[13]}$.

\subsubsection{Wear resistance}

Electroless nickel is most frequently used in wear applications in the precipitationhardened condition. The coatings are characterized by high hardness and wear resistance. They are even further increased by heat treatment. Heating for $1 \mathrm{~h}$ at $400^{\circ} \mathrm{C}$ results in optimum hardness, which is comparable to 'hard' chromium deposits in hardness and wear resistance ${ }^{[13,83,88]}$. Long-term treatments (30 to 40 weeks) at temperatures around $290^{\circ} \mathrm{C}$ can produce hardness values of 1700 to $2000 \mathrm{HV}_{0.1}{ }^{[14,61]}$. These low-temperature treatments result in a finer dispersion of nickel boride than do higher temperatures and in the formation of iron borides (such as $\mathrm{Fe}_{2} \mathrm{~B}$ and $\mathrm{Fe}_{3} \mathrm{C}_{0.2} \mathrm{~B}_{0.8}$ ) within the coating, when the substrate is ferrous alloy. Fig. 7 shows that low phosphorus is better than high phosphorus, and heat treated Ni-B has comparable wear resistance to hard chrome ${ }^{[83,90-91]}$.
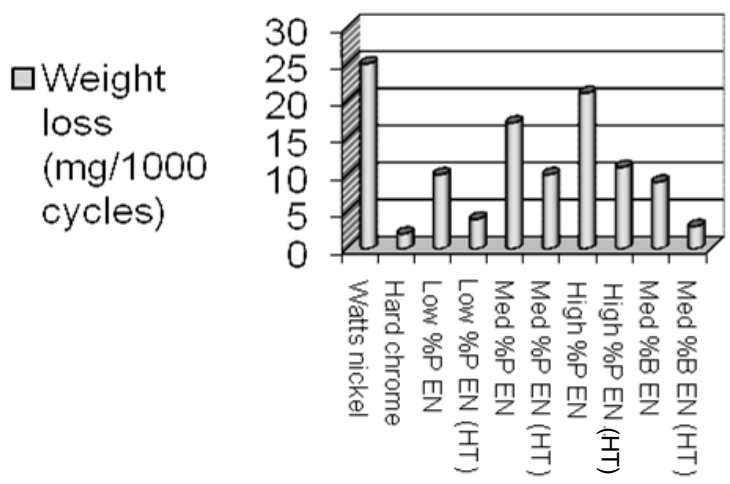

Fig. 7. Taber wear resistance of various kinds of coating. 
Sahoo optimized the coating process parameters for the minimum wear based on $\mathrm{L}_{27}$ Taguchi orthogonal design with four process parameters, namely bath temperature, concentration of nickel source solution, concentration of reducing agent, and annealing temperature. Result reveals that annealing temperature and bath temperature have the most significant influence in controlling wear characteristics. The interaction of bath temperature and concentration of nickel source solution has some significant influence ${ }^{[92-93]}$. Wear performance on self-mated groups of $\mathrm{Ni}, \mathrm{Cu}$, and $\mathrm{Ni}-\mathrm{P}$ coatings has been examined by electroless Ni-P coating onto the friction surfaces. The electroless Ni-P coating during friction enhances the growth of transfer particles in $\mathrm{Cu} / \mathrm{Cu}$ and $\mathrm{Ni} / \mathrm{Ni}$ rubbing systems. The particles were harder than the original surface due to the inclusion of coating material. This is the reason of the increment of the growth of transfer particles incorporated with the coating during friction ${ }^{[94]}$.

The widest use of electroless nickel for both corrosion and wear resistance is in valves that control the flow of either liquids or gases. Other uses ${ }^{[15]}$ of electroless nickel in wear applications include aluminum piston heads, aircraft engine shafts, components of gas turbines and engine mounts in the aircraft industry, and such automotive parts as differential pinion ball shafts, fuel injectors, ball studs, disk brake pistons, transmission thrust washers, knuckle pins, and hose couplings. In mining applications and associated material-handling equipment, where abrasive wear conditions prevail, electroless nickel has been substituted for hard chromium. A very important application of electroless nickel is the salvage of worn surfaces, especially because it is possible to coat only specific areas. Thus, little or no subsequent machining or grinding is required. The inclusion in electroless-nickel deposits of hard (silicon carbide or boron nitride) or solid-lubricant particles (PTFE) can also improve their tribological properties, which will be discussed more in the electroless composite coating section. 


\subsubsection{Frictional properties}

This also vary with phosphorus/boron contents and with heat treatment. They are similar to those of chromium. The phosphorus content provides natural lubricity, which can be very useful for applications such as plastic molding. The coefficient of friction for electroless nickel/boron versus steel is 0.12 to 0.13 for lubricated conditions and 0.43 to 0.44 for un-lubricated conditions ${ }^{[95]}$. Coefficients of friction of chromium coating, electroless nickel (EN) in the as-deposited condition and after heat treating at $400^{\circ} \mathrm{C}$ (EN400) and at $600^{\circ} \mathrm{C}\left(\mathrm{EN600)}\right.$ are listed in Table $7^{[96]}$. The counter surfaces were diamond and plain carbon steel. The coefficients of friction of the electroless nickels are higher than those of the chromium deposits.

Table 7: Coefficients of friction of chromium versus electroless nickel

\begin{tabular}{lll}
\hline Coating & Counterface diamond & Counterface plain C steel (080M40) \\
\hline Cr & $0.03-0.04$ & $0.81-0.88$ \\
EN & 0.18 & 0.96 \\
EN400 & 0.30 & 0.95 \\
EN600 & 0.06 & 0.90 \\
\hline
\end{tabular}

\subsection{Corrosion}

The single most widespread application of electroless nickel is to provide superior corrosion protection in multitudinous corrosive environments. Electroless nickel coating is noble than steel and aluminum. It protects the substrate by providing a pore free barrier coating. Due to its amorphous nature in high phosphorus and passivity, the corrosion resistance of the coating is excellent and in many environments, superior than pure nickel or 
chromium alloys. Amorphous alloys have better corrosion resistance to attack than corresponding polycrystalline materials. Alloys containing high $\mathrm{P}$ are more resistant to attack than those with lower phosphorus contents ${ }^{[28]}$ in neutral or acidic environments. Alloys containing low phosphorus (3-4\%) are more resistant to strong alkaline environments than high phosphorus deposits. Heat treatment on electroless nickel starts forming nickel phosphide around $250^{\circ} \mathrm{C}$, reducing the phosphorus content of the remaining material. This reduces the corrosion resistance of the coatings. The Ni-B alloy coatings are less corrosion resistant than that of high phosphorus Ni-P alloys and this can also be revealed by Table $8{ }^{\text {[90, }}$ 97]. In addition to the results given in the table, tests show nil corrosion rate of both coatings in benzene, brine ( $3.5 \%$ salt, $\mathrm{H}_{2} \mathrm{~S}$ saturated, $95^{\circ} \mathrm{C}$ ), carbon tetrachloride, potassium hydroxide (50\%), sodium hydroxide (45\%), water (distilled, $\mathrm{N}_{2}$ deaerated, $100^{\circ} \mathrm{C}$ ), water (distilled, $\mathrm{O}_{2}$ saturated, $95^{\circ} \mathrm{C}$ ), and water (sea, $3.5 \%$ salt, $95^{\circ} \mathrm{C}$ ), all at $20^{\circ} \mathrm{C}$ unless specified otherwise.

In petroleum industry, long tubes are used for heat exchange, and these pipes were made of stainless steel which is gradually replaced by electroless nickel plated steel as it is cheaper than stainless steel. However, electroless coating has many pin-holes due to hydrogen bubble evolution during electroless deposition. These pin-holes reduce the corrosion protection ability of the coating. Sol-gel ceramic coating on electroless nickel deposit reduces the pin-holes on the surface. Single layer of different inorganic and hybrid ceramic sols has been coated on electroless Ni-P coated mild steel followed by heat treatment at $400^{\circ} \mathrm{C}$ for $1 \mathrm{~h}$. Hybrid/inorganic silica, alumina and yttria stabilized zirconia sols were used to enhance the corrosion resistance of electroless coating without modifying its other properties. Addition of inorganic molybdenum salt or chromate into the Ti sol also improves the wearing quality of the sol-gel film on electroless nickel ${ }^{[98]}$. 
Table 8: Corrosion rate ( $\mu$ m/year) of electroless Ni-P (11-12\% P) and Ni-B (4-5\% B) coatings in different environment at $20^{\circ} \mathrm{C}$ except where specified in brackets

\begin{tabular}{|c|c|c|}
\hline Environment & Ni-P (11-12\% P) & Ni-B (4-5\% B) \\
\hline Acetic acid, glacial & 0.8 & 84 \\
\hline Acetone & 0.08 & Nil \\
\hline Aluminum sulfate, $27 \%$ & 5 & - \\
\hline Ammonia, 25\% & 16 & 40 \\
\hline Ammonium nitrate, $20 \%$ & 15 & Very rapid \\
\hline Ammonium sulfate, saturated & 3 & 3.5 \\
\hline Brine, $3.5 \%$ salt, $\mathrm{CO}_{2}$ saturated $\left(95^{\circ} \mathrm{C}\right)$ & 5 & - \\
\hline Calcium chloride, $42 \%$ & 0.2 & - \\
\hline Citric acid, saturated & 7 & 42 \\
\hline Cupric chloride, $5 \%$ & 25 & - \\
\hline Ethylene glycol & 0.6 & 0.2 \\
\hline Ferric chloride, $1 \%$ & 200 & - \\
\hline Formic acid, 88\% & 13 & 90 \\
\hline Hydrochloric acid, 5\% & 24 & - \\
\hline Hydrochloric acid, 2\% & 27 & - \\
\hline Lactic acid, 85\% & 1 & - \\
\hline Lead acetate, 36\% & 0.2 & - \\
\hline Nitric acid, 1\% & 25 & - \\
\hline Oxalic acid, 10\% & 3 & - \\
\hline Phenol, 90\% & 0.2 & Nil \\
\hline Phosphoric acid, 85\% & 3 & Very rapid \\
\hline Sodium carbonate, saturated & 1 & Nil \\
\hline Sodium hydroxide, $50 \%\left(95^{\circ} \mathrm{C}\right)$ & 0.2 & - \\
\hline Sodium sulfate, $10 \%$ & 0.8 & 11 \\
\hline Sulfuric acid, 65\% & 9 & - \\
\hline Water, acid mine, $3.3 \mathrm{pH}$ & 7 & - \\
\hline
\end{tabular}




\section{Electroless nickel composite coatings}

The co-deposition of composite materials (hard particle or non-metallic) with electroless coatings is termed as electroless composite coatings. Wear-resistant composite can be produced by the co-deposition of fine particulate matter. Hard particles, such as diamond, silicon carbide, aluminum oxide, and solid lubricants, such as polytetrafluoroethylene (PTFE) particles, have been co-deposited. Other small particles of intermetallic compounds, and fluorocarbons can disperse in an electroless nickel-phosphorus/boron matrix. Electroless composite coatings were not successful initially and often resulted in decomposition of the bath. This is because of the dispersion of fine particles increases the surface area loading of the electroless bath by nearly 700-800 times of that of normal electroless bath and this leads to instability of the bath. Nevertheless, with the aid of suitable stabilizers, electroless nickel composite coating was prepared. In contrast to electro co-deposition, electroless coating allows accurate reproduction of the surfaces and avoids the subsequent mechanical finishing $[24,26]$

This coating is developed by the impact and settling of particles on the surface of the work piece, and the subsequent surrounding of these particles by the Ni-P matrix as it is deposited. There is no molecular bonding between the metal matrix and the incorporated fine particles. Guglielmi proposed a mathematical model for the electro-deposition process of composite coatings. Experimental results are in agreement with the mechanism proposed by Guglielmi ${ }^{[99]}$. Grosjean et al. used an experimental set-up used for producing electroless nickel-SiC composite coatings, shown in Fig. $8^{[100]}$, where agitation induced by the fluid circulation with a centrifugal pump and a waterfall system was used. Thus, the circulation of the bath from top to bottom created a laminar flow of the fluid on the surface of the sample. This type of cell, with upward circulation, provided the agitation and had the advantage of keeping the particles suspended in the solution. 
Table 9: Compositions and plating conditions for EN-SiC/PTFE/TiO $/ 2 \mathrm{SiO}_{2}$ composite coatings

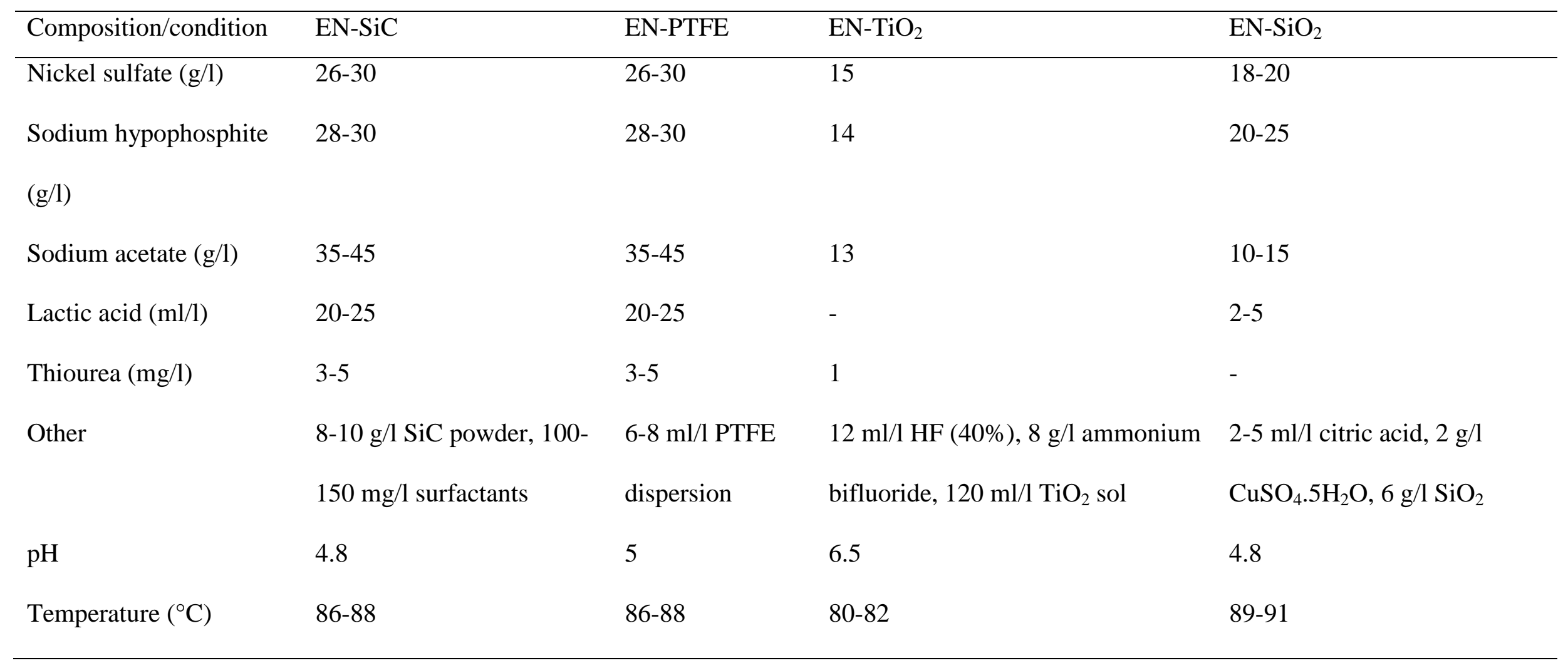




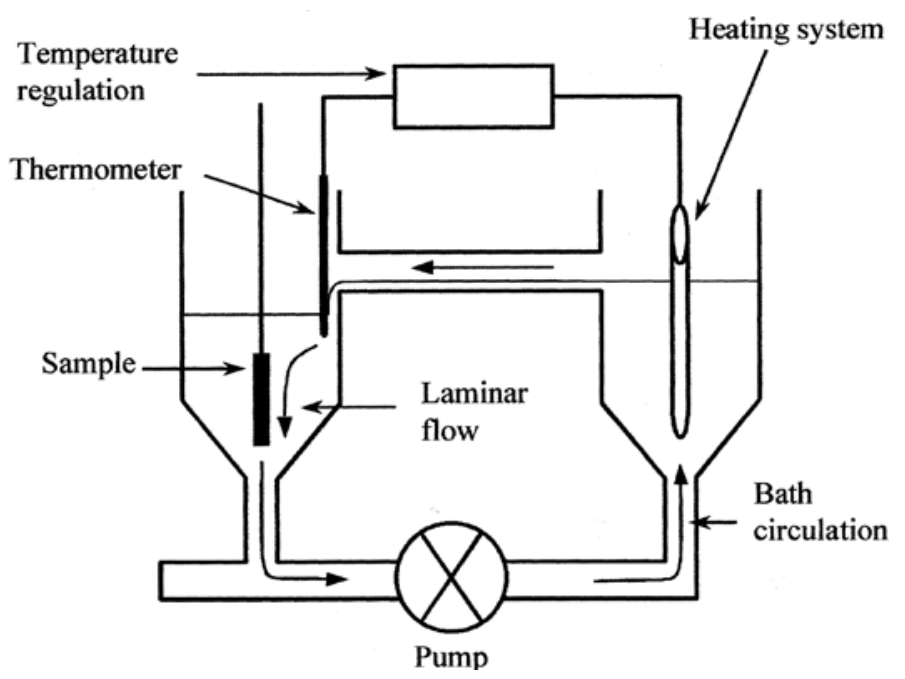

Fig. 8. Experimental set-up recommended for producing electroless composite coatings.

Typical compositions of EN-PTEF, EN-SiC, EN-TiO ${ }_{2}$ and EN-SiO ${ }_{2}$ composite baths and their plating conditions are as shown in Table 9.

The particle dimension ranges from sub micron alumina and PTFE to 5-micron diamonds ${ }^{[101]}$. In order to achieve better integrity between the particles and the electroless nickel-phosphorus matrix, the size of the particles should be small so that they can be firmly held by the matrix ${ }^{[102]}$. Apachitei et al. ${ }^{[103]}$ showed that the spherical shaped $\mathrm{Al}_{2} \mathrm{O}_{3}$ particles had better incorporation than irregular ones. The difference in particle shape also has a bearing on the type of finish of the deposit. Very rough and very smooth surfaces were resulted, respectively, from large angular and small rounded particles. The particles like silicon carbide $(\mathrm{SiC})^{[103-105]}$, chromium carbide $(\mathrm{CrC})$, zirconia or aluminum oxide $\left(\mathrm{ZrO}_{2}\right.$, $\mathrm{Al}_{2} \mathrm{O}_{3}$ ), graphite and PTFE ${ }^{[106]}$ have been investigated by many authors. The essential requirements of electroless nickel composite coating are summarized below.

(1) Bath stability. The dispersion of fine particles increases the surface area loading and leads to decomposition of the bath ${ }^{[102]}$.

(2) Agitation. Hard particles, such as diamond, silicon carbide, and aluminum oxide are kept in suspension by agitation and become occluded in the deposit. It is recommended that the objects be rotated and/or tumbled in such a way that all parts of 
the surface are regularly presented upwards. Agitation of the plating solution is a key factor $^{[107-108]}$.

(3) Particles size. Particles of suitable shape and size must be insoluble in the solution, free from surface contaminants and should be kept in suspension of the bath. Particle size plays a vital role in the deposit ${ }^{[103]}$.

(4) Concentration of the particles. Beyond some critical concentration, there is a possibility of agglomeration of these second phase particles due to the decrease in the mean distance between them resulting in settlement of the particles, causing either saturation or slight decrease in the level of incorporation. Concentration is very important in distribution of particles in the deposit ${ }^{[109-111]}$.

(5) Surfactants. These additives are especially important in the incorporation of soft particles like polytetrafluoroethylene (PTFE), graphite and molybdenum disulfide. Surfactants play a major role in the incorporation of second phase particles ${ }^{[112-113]}$. As mentioned above, concentration of the dispersed particles in the electroless nickel bath plays a major role in influencing the incorporation level. Every composite has its special characters. 20 to $25 \%$ SiC by volume has found maximum hardness, higher than Ni-P alloy coating. 20 to $25 \%$ PTFE by volume has been found to reduce the friction between engineering components plated with them. These composites are standard commercial ones, particularly when the wear resistance or a low coefficient of friction is required. Graphite is an alternative for PTFE but PTFE is having sound industrial application ${ }^{[114]}$.

Sodium dodecyl sulfate (SDS) is used to increase the dispersion and wettability of the SiC particles. Grosjean et al. showed that with the addition of Forafac-500, the co-deposition of SiC particles could be raised from 19 to 53 vol.\% ${ }^{[115]}$. Ger and Hwang proposed that the surfactant addition enabled a higher level of incorporation of PTFE particles and their concentration in the bath was critical ${ }^{[113]}$. It is inferred from the above that several factors 
affect the incorporation of second phase particles in the electroless nickel-phosphorus/boron matrix, under the actual process conditions. Ger et al. in another study ${ }^{[116]}$ utilized two surfactant (cetyl trimethyl ammonium bromide (CTAB) and FC134) in Ni-P-PTFE plating for comparison. The composition variation of the coating is strongly related to the cathodic reactivity of the surfactants depending on the substrates at the early stage. The cathodic reactivity of the surfactants is higher; simultaneously the PTFE particles are more easily embedded in the co-deposition. The volume fraction of PTFE loading increases with the growth of the co-deposition coating, when the cathodic reactivity of surfactants on a substrate is lower than that on the deposited layer. Increasing the PTFE volume fraction loading with the growth of the co-deposition layer would provide good adhesion between the substrate/codeposition layers. In a recent study, the addition of PTFE and the proper type and concentration of surfactants created uniform distribution of PTFE particles in the Ni-P matrix. CTAB and poly-vinylpyrrolidone (PVP) make a uniform distribution of PTFE particles in the coating, whereas SDS does not ${ }^{[117]}$. A deep understanding of the influence of process parameters and conditions on electroless nickel deposits and the characteristic properties of the second phase particles used for incorporation is an essential first step to get good composite incorporation.

The weight percentage of hard and soft particles co-deposited in the electroless NiP/B can be determined by dissolving a known weight of the deposit in nitric acid and then filtering the particles through a weighed $0.1 \mu \mathrm{m}$ membrane ${ }^{[118]}$. There are many other methods proposed to determine the incorporation level of second phase particles in electroless nickel-phosphorus/boron matrices, such as, electron microprobe analyzer (EPMA) for the incorporation of $\mathrm{Cr}_{3} \mathrm{C}_{2}{ }^{[119]}$ and by the cross-section of the coating using image analysis, proposed by Bozzini et al. ${ }^{[120]}$, also used by Pena-Munoz et al. ${ }^{[121]}$ and Straffelini et al. ${ }^{[122]}$. Yu and Zhang proposed the use of plasma emitting spectrum analyzer, which can 
directly determine the coating constituents ${ }^{[123]}$. Even further, Losiewicz et al. adopted the method of particle counting by observation of the coating surface morphology of EN$\mathrm{TiO}_{2} / \mathrm{PTFE}^{[124]}$. These methods could be helpful for determining the particle incorporation in electroless composite coatings.

\subsection{Structure}

The incorporation of $\mathrm{Si}_{3} \mathrm{~N}_{4}, \mathrm{CeO}_{2}$ and $\mathrm{TiO}_{2}$ particles does not change the structure of the electroless Ni-P matrix deposit ${ }^{[125]}$. However, the incorporation of $\mathrm{B}_{4} \mathrm{C}$ particles is found to affect the orientation of nickel crystallites without influencing the crystallite dimensions; nickel tends to be less oriented in layers with $\mathrm{B}_{4} \mathrm{C}$ particles ${ }^{[120]}$. Balaraju and Rajam ${ }^{[126]}$ observed that the incorporation of $\mathrm{Si}_{3} \mathrm{~N}_{4}$ particles in electroless $\mathrm{Ni}-\mathrm{P}$ matrix has not influenced the structure of the composite coating, whereas Apachitei et al. ${ }^{[127]}$ observed the $\mathrm{SiC}$ reflection in the XRD pattern of as-deposited electroless Ni-P-SiC composite coating and it might be due to the higher amount of particles co-deposition ( 7 wt.\%). Jiaqiang et al. observed the incorporation of $\mathrm{SiC}$ particles in electroless $\mathrm{Ni}-\mathrm{P}$ matrix, where the coating crystallized into nickel crystal, nickel phosphide and nickel silicides after heat treating at $400^{\circ} \mathrm{C}$ for $1 \mathrm{~h}$. After heat treating at $600^{\circ} \mathrm{C}$, there is no special diffraction peak of nickel

silicides except for $\mathrm{Ni}_{3} \mathrm{Si}$, whose lattice approaches that of nickel ${ }^{[128]}$. The final products of the crystallization and reaction of composite coatings were $\mathrm{Ni}, \mathrm{Ni}_{3} \mathrm{P}, \mathrm{Ni}_{3} \mathrm{Si}$ and free carbon.

\subsection{Hardness, friction, wear and abrasion resistance}

These composite coatings are claimed to have much more improved hardness properties for tools used at ambient temperatures, such as molds, extruders for plastics, metal patterns, core boxes for castings, forging dies and dies for casting of zinc alloys. The average hardness of some electroless Ni-P composite coatings is presented in Table 10. 
Table 10: Hardness of electroless nickel composite coatings

\begin{tabular}{|c|c|c|}
\hline Coating & As-deposited & $\begin{array}{l}\text { Heat-treated } \\
\left(400^{\circ} \mathrm{C} / 1 \mathrm{~h}\right)\end{array}$ \\
\hline $\mathrm{Ni}-\mathrm{P}^{[120]}$ & $528 \pm 62 \mathrm{HV}_{0.1}$ & $809 \pm 41 \mathrm{HV}_{0.1}$ \\
\hline Ni-P (9 vol.\%)-B 4 C (25 vol.\%) ${ }^{[120]}$ & $672 \pm 93 \mathrm{HV}_{0.1}$ & $952 \pm 114 \mathrm{HV}_{0.1}$ \\
\hline Ni-P-MoS 2 (5 vol.\%) ${ }^{\lfloor 122\rfloor}$ & $680 \mathrm{HK}_{0.05}$ & - \\
\hline Ni-P-PTFE ${ }^{[129]}$ & $340 \mathrm{HV}_{0.05}$ & $421 \mathrm{HV}_{0.05}$ \\
\hline Ni-P-SiC (25 vol.\%) ${ }^{[129]}$ & $530 \mathrm{HV}_{0.05}$ & $1365 \mathrm{HV}_{0.05}$ \\
\hline $\mathrm{Ni}-\mathrm{P}\left(7.2\right.$ wt.\%)- $\mathrm{Cr}_{2} \mathrm{C}_{3}\left(27\right.$ vol.\%) ${ }^{\lfloor 119\rfloor}$ & $645 \mathrm{HV}_{100}$ & - \\
\hline Ni-P-CNT (11.2 vol.\%) $)^{\lfloor 130\rfloor}$ & $1524 \mathrm{HV}_{50}$ & - \\
\hline Ni-P (5.5 wt.\%)-BN(h) (33 vol.\%) ${ }^{[131\rfloor}$ & $486 \mathrm{HK}_{0.1}$ & $753 \mathrm{HK}_{0.1}$ \\
\hline Ni-P (10.5 wt.\%)-SiC with $1 \mu \mathrm{m}$ size (3.8 wt.\%) ${ }^{\lfloor 128\rfloor}$ & $580 \mathrm{HV}_{0.05}$ & $1206 \mathrm{HV}_{0.05}$ \\
\hline Ni-P (10 wt.\%)-Si ${ }_{3} \mathrm{~N}_{4}\left(8.1\right.$ wt.\%) ${ }^{[126]}$ & $655 \mathrm{HV}_{0.05}$ & $1220 \mathrm{HV}_{0.05}$ \\
\hline Ni-P-nano $\mathrm{SiO}_{2}\left(6\right.$ wt.\%) ${ }^{[132]}$ & $320 \mathrm{HV}_{0.02}$ & $1320 \mathrm{HV}_{0.02}$ \\
\hline Ni-P-novel $\mathrm{TiO}_{2}\left(3.7\right.$ wt.\%) ${ }^{\lfloor 118\rfloor}$ & $1025 \mathrm{HV}_{0.2}$ & 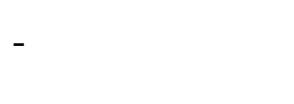 \\
\hline Ni-P (8.22 wt.\%)- $\mathrm{Al}_{2} \mathrm{O}_{3}\left(28.6\right.$ vol.\%) ${ }^{\lfloor 103\rfloor}$ & $743 \pm 15 \mathrm{HV}_{0.1}$ & $1248 \pm 68 \mathrm{HV}_{0.1}$ \\
\hline Ni-P (10.18 wt.\%)-CeO 2 (7.44 wt.\%) ${ }^{\lfloor 24\rfloor}$ & $676 \mathrm{HV}_{0.1}$ & $1136 \mathrm{HV}_{0.1}$ \\
\hline Ni-Zn (6.8 wt.\%)-P (10.56 wt.\%)- $\mathrm{TiO}_{2}$ (2.3 wt.\%) & $250 \mathrm{HV}_{0.1}$ & $350 \mathrm{HV}_{0.1}$ \\
\hline Ni-W (1.01 wt.\%)-P (10.3 wt.\%)- $\mathrm{Al}_{2} \mathrm{O}_{3}{ }^{[134]}$ & $581 \pm 18 \mathrm{HV}_{0.05}$ & $1178 \pm 48 \mathrm{HV}_{0.05}$ \\
\hline Ni-P (2.1 wt.\%)-C with 4-8 $\mu \mathrm{m}$ size (71.1 wt.\%) ${ }^{[135]}$ & $642 \mathrm{HV}_{0.05}$ & - \\
\hline
\end{tabular}

The amount of co-deposition particles, the phosphorus content of the matrix and heattreatment determine the hardness of these coatings. The coating hardness increases with the increased amount of hard particles (such as $\mathrm{SiC}, \mathrm{Si}_{3} \mathrm{~N}_{4}$ ) in the coating ${ }^{[120,126,128]}$, whereas hardness decreases with the soft particles (such as PTFE) ${ }^{[129]}$. Hard particles are mainly 
responsible for an increase in hardness, at all phosphorus contents (2-14 wt.\% P). The effect of heat treatment in the composite coating on hardness has similar trend of that in plain electroless Ni-P deposit. The hardness increases up to $400^{\circ} \mathrm{C}$ is due to precipitation hardening by the formation of intermetallic $\mathrm{Ni}_{3} \mathrm{P}$ phase. The hardness decreases beyond $400^{\circ} \mathrm{C}$, due to decrease in lattice defects and coarsening of the $\mathrm{Ni}_{3} \mathrm{P}$ particles ${ }^{[88]}$. Dong et al. reported that the $\mathrm{SiO}_{2}$ nanoparticles were capable of significantly improving the mechanical properties of electroless Ni-P coating, leading to greatly increased microhardness $\left(\sim 400^{\circ} \mathrm{C}\right)$ and wear resistance ${ }^{[132]}$. Chen et al. ${ }^{[118]}$ developed a novel $\mathrm{Ni}-\mathrm{P}-\mathrm{TiO}_{2}$ composite coating technique by adding transparent $\mathrm{TiO}_{2}$ sol into the conventional electroless plating solution. The microhardness has been significantly improved from $\sim 710 \mathrm{HV}_{0.2}$ of the conventional Ni-P$\mathrm{TiO}_{2}$ coating to $1025 \mathrm{HV}_{0.2}$ (Table 10 ). The Ni-Zn-P-TiO${ }_{2}$ composite coatings exhibited higher microhardness than pure Ni-Zn-P alloy ${ }^{[133]}$.

Friction is the resistance to motion, when bodies slide over each-other ${ }^{[136]}$. By the means of coatings, the surface can be imparted from dry lubrication. In electroless Ni-P deposit, the natural lubricity of phosphorus provides a good lubrication property. Nevertheless, under unlubricated conditions, prolonged friction results in galling or seizure failure of electroless Ni-P deposits, but electroless nickel composite deposits can have reduced such failures. The hard particles such as SiC exhibit poor lubrication property, when compared with electroless Ni-P deposit. This is because of the high surface roughness and high mechanical interlocking force of the hard particles ${ }^{[105]}$. On the other hand, electroless Ni-P matrix co-deposited with soft particles such as PTFE and graphite provides good lubrication, under unlubricated conditions due to their ability to prevent adhesion between the mating surfaces. Ebdon ${ }^{[137-138]}$ reported that the low coefficient of friction is due to the transfer of PTFE to the counter face material. The Ni-P-PTFE deposits ${ }^{[139-140]}$ have lower average coefficient of friction $\left(\mu_{\mathrm{av}}\right)$ compared to electroless Ni-P deposits, in both as-plated 
and heat treated $\left(400^{\circ} \mathrm{C} / 1 \mathrm{~h}\right)$ conditions and $\mu_{\mathrm{av}}$ is an inverse function of PTFE content. The deposits possess excellent lubrication properties in the range from very low temperature to $290^{\circ} \mathrm{C}$. Furthermore, the electroless Ni-P-graphite (6 vol.\%) deposits fail to provide efficient lubrication, when sliding against a steel counter face ${ }^{[114]} \cdot \mu_{\mathrm{av}}$ is low when electroless Ni-Pgraphite composite deposit is sliding against itself. Hexagonal boron nitride, molybdenum disulfide, inorganic fullerene-WS $\mathrm{W}_{2}$ and carbon nanotubes are the other particles capable of providing a low $\mu_{\mathrm{av}}$ when incorporated in the electroless Ni-P matrix ${ }^{[112,141]}$.

The primary use of electroless Ni-P composite deposit is for the applications requiring maximum resistance to wear and abrasion ${ }^{[114]}$. Metzger and Florian ${ }^{[142]}$, Parker ${ }^{[143]}$ and Feldstein et al. ${ }^{[23]}$ reviewed the wear resistance of electroless Ni-P composite deposits with various hard particles (Fig. 9). It is evident that the wear resistance of electroless composite deposit is equivalent to hard chromium. Like hardness, the wear resistance of electroless Ni-P composite deposits is also influenced by the type of hard particle co-deposited, its amount of incorporation and its size. Straffelini et al. ${ }^{[122]}$ suggest that wear of electroless Ni-P composite deposits occurs in two stages. In the first stage, the deposits undergo a mild abrasive wear with the initial wear damage which reflects the surface durability, whereas in the second stage the wear is severe and characterized by the brittle detachment of debris.

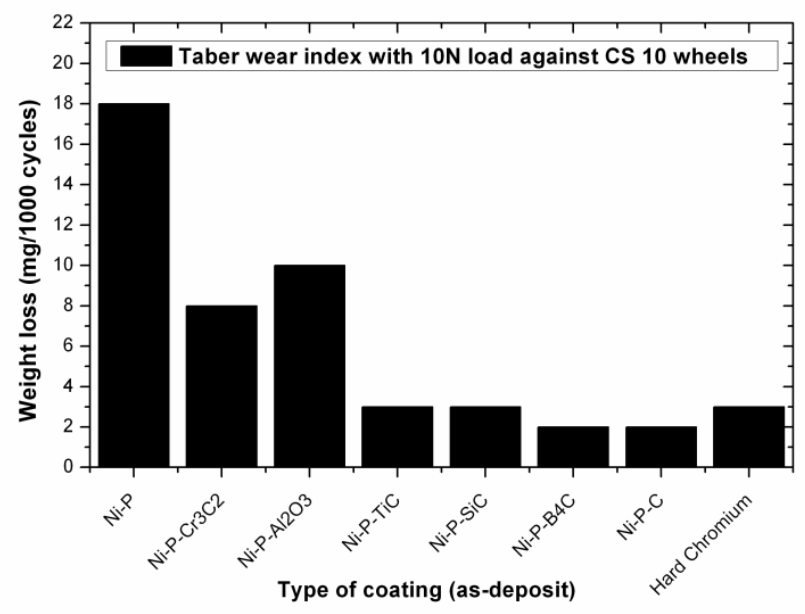

Fig. 9. Taber wear of electroless nickel composite coatings. 
Wear resistance of electroless Ni-P-SiC composite deposits has been studied by many researchers ${ }^{[104,127-129]}$. The wear resistance increases with increase in SiC incorporation level. The dispersion strengthening effect of SiC particles and the strong Ni-P matrix enables such coatings to offer excellent wear resistance. Furthermore, the Ni-P matrix should posses high phosphorus content ( $>7 \mathrm{wt} . \%$ ) in order to support the SiC particle to provide superior wear resistance (in both as-deposit and heat-treated conditions). The influence of heat treatment on the wear resistance of electroless Ni-P-SiC composite deposits suggests that wear resistance increases with increase in heat-treatment temperature up to $350^{\circ} \mathrm{C}^{[144]}$. Further increase in temperature (up to $600^{\circ} \mathrm{C}$ ) results in increase in the wear rate with further deterioration at higher temperatures $\left(\sim 800^{\circ} \mathrm{C}\right)$. The possible reaction between nickel and $\mathrm{SiC}$ at around $580^{\circ} \mathrm{C}$ and a partial melting of $\mathrm{Ni}-\mathrm{P}$ eutectic at $880^{\circ} \mathrm{C}$ are responsible for the poor wear resistance at high temperatures. The formation of nickel silicide $\left(\mathrm{Ni}_{3} \mathrm{Si}\right)$ is influenced by the diffusion of nickel atoms into the SiC lattice and it occurs at the SiC/Ni-P matrix interface upon heattreatment at $500^{\circ} \mathrm{C}$ for $1 \mathrm{~h}$. The $\mathrm{Ni}_{3} \mathrm{Si}$ formation increases the adhesion between the reinforcement and the matrix but decreases the wear resistance ${ }^{[127,145]}$. The co-deposit of $\mathrm{Cr}_{3} \mathrm{C}_{2}$ particles (27 vol.\%) in the Ni-P matrix increases the wear resistance ${ }^{[119]}$. Heattreatment at $400^{\circ} \mathrm{C}$ for $1 \mathrm{~h}$ further enhances the wear resistance of these deposits. Even asplated electroless Ni-P-hexagonal boron nitride $(\mathrm{BN}(\mathrm{h}))$ composite deposit is giving higher wear resistance than plain electroless Ni-P deposit heat-treated at $400^{\circ} \mathrm{C}$ for $1 \mathrm{~h}^{[146]}$. Wear decreased by nearly two orders of magnitude when the Ni-P matrix is incorporated with 33 vol.\% $\mathrm{BN}(\mathrm{h})$ particles ${ }^{[147]}$. At $400^{\circ} \mathrm{C}$, a mixed adhesive and fatigue wear mechanism, accompanied by large plastic deformation of deposits and high deposit transfer to the counterface material was noticed ${ }^{[148]}$. This shows that the tribological response of composite deposits at high temperatures is related to the mechanical properties of the Ni-P matrix, that is, to its behavior to withstand the applied stresses as the temperature increases, regardless of the 
nature and properties of the incorporated particles. Reddy et al. ${ }^{[102]}$ reported the wear resistance of electroless Ni-P matrix with diamond (C) particles of different size ranges (3-40 $\mu \mathrm{m})$. Coatings with finer $\mathrm{C}$ particles (3-6 $\mu \mathrm{m}$ ) are more wear resistant compared to those with coarse particles (20-40 $\mu \mathrm{m})$. This influence is largely a function of the degree of co-deposited of $\mathrm{C}$ particles for a given coating thickness, which is higher for finer $\mathrm{C}$ particles. This was again confirmed by a recent study. These coatings exhibit better wear-resistance (for 4-8 $\mu \mathrm{m}$ ) when compared to coatings dispersed with larger diamond particles ${ }^{[135]}$. Winowlin Jappes et al. ${ }^{[149]}$ adapted the concept of internal standard method of quantitative XRD analysis with suitable modifications for the study of removal of diamond particles from the Ni-P-C matrix. Superior integrity of the $\mathrm{C}$ particles with the matrix of the coating is observed for the specimens, when heat treated at $\sim 350^{\circ} \mathrm{C}$ because of the formation of phosphides. Increasing the heat treatment to $\sim 500^{\circ} \mathrm{C}$ affects the wear resistance. In addition, a new approach on wear analysis by pasting silver foil on the specimen is introduced. Hard particles, such as tungsten carbide and diamond, cause pronounced abrasion of the counterface materials ${ }^{[143]}$. Similarly, higher levels of $\mathrm{B}_{4} \mathrm{C}$ particles incorporated in the Ni-P matrix are found to increase the wear resistance $^{[120]}$.

\subsection{Corrosion and other properties}

Generally, the wear resistance of composite coatings is significantly higher, but corrosion resistance is lower than that of plain electroless Ni-P deposits. Electroless Ni-P$\mathrm{Si}_{3} \mathrm{~N}_{4}$ composite coatings in $3.5 \mathrm{wt} \% \mathrm{NaCl}$ solution shows a marginal increase in corrosion resistance compared to plain electroless Ni-P deposit. In some cases, electroless $\mathrm{Ni}-\mathrm{P}-\mathrm{Si}_{3} \mathrm{~N}_{4}$, $\mathrm{Ni}-\mathrm{P}-\mathrm{CeO}_{2}$ and $\mathrm{Ni}-\mathrm{P}-\mathrm{TiO}_{2}$ composite coatings, by electrochemical impedance spectroscopy,

show better corrosion resistance than the plain electroless Ni-P deposits ${ }^{[150-151]}$. The corrosion resistance is better in the $\mathrm{CeO}_{2}$-containing coating, due to its smaller liability to 
undergoing local-cell corrosion than its $\mathrm{CeO}_{2}$-free counterpart. In a recent study, the electroless $\mathrm{Ni}-\mathrm{P}-\mathrm{Fe}_{3} \mathrm{O}_{4}$ composite coatings exhibited better corrosion resistance than plain Ni$\mathrm{P}$ coatings at room temperature in 3.5 wt.\% $\mathrm{NaCl}$ solution ${ }^{[152]}$. The incorporation of $\mathrm{TiO}_{2}$ in $\mathrm{Ni}-\mathrm{Zn}-\mathrm{P}$ coatings gives good corrosion resistance in $3.5 \mathrm{wt} . \% \mathrm{NaCl}$ solution ${ }^{[133]}$.

Surface roughness $\left(\mathrm{R}_{\mathrm{a}}\right)$ is an important parameter as it provides the metal contact area between materials, which in turn increases the friction resistance, friction coefficient etc. ${ }^{[23]}$. Co-deposition of hard and soft particles in the electroless Ni-P matrix changes the surface finish in terms of both brightness and $R_{a}$. The hard particles increases the $R_{a}$, whereas soft particles decreases the $\mathrm{R}_{\mathrm{a}}$, when compared to that of plain electroless Ni-P deposit ${ }^{[23]}$. The effect of $\mathrm{R}_{\mathrm{a}}$ with the co-deposited hard and soft particles is dependent upon various parameters such as the type of particle, particle size, volume fraction of the particles and the thickness of the coating ${ }^{[23]}$. Zhao et al. ${ }^{[153]}$ reported that incorporation of $\mathrm{Cu}$ in the electroless Ni-P-PTFE matrix increased the deposition rate and corrosion resistance. 6.5 wt.\% $\mathrm{Cu}$ content in the deposit was found to be the best (with $\mathrm{pH}-7,85^{\circ} \mathrm{C}$, and $0.5 \mathrm{~g} / \mathrm{l} \mathrm{CuSO} \mathrm{Cu}_{4} .5 \mathrm{H}_{2} \mathrm{O}$ as plating parameters).

The oxidation property of these deposits is scarcely measured. The addition of $\mathrm{B}_{2} \mathrm{O}_{3}$ to a Ni-P mixture decreased the extent of oxidation. Similarly, it was found that incorporation of $\mathrm{Si}_{3} \mathrm{~N}_{4}$ (8.01 wt.\%), $\mathrm{CeO}_{2}$ (7.44 wt.\%) or $\mathrm{TiO}_{2}$ (5.42 wt.\%) in an electroless Ni-P matrix increased the oxidation resistance and the extent of increase was a function of the amount of particles co-deposited. The electroless $\mathrm{Ni}-\mathrm{P}-\mathrm{Fe}_{3} \mathrm{O}_{4}$ composite coatings exhibited better resistance to cyclic oxidation test in air at $800^{\circ} \mathrm{C}$. The oxidation behavior followed a parabolic rate law, with the following compounds from outside: $\mathrm{Ni}$ oxide/Ni phosphides (and spinels in Ni-P-Fe $\mathrm{O}_{4}$ coatings, possibly formed by the presence of magnetite)/ $/ \mathrm{Cr}_{2} \mathrm{O}_{3}$ and Ni$\mathrm{Cr}$ spinels. The oxide scale in $\mathrm{Ni}-\mathrm{P}-\mathrm{Fe}_{3} \mathrm{O}_{4}$ coatings was more compact. There was deviation from parabolic kinetics when temperature rises to $900^{\circ} \mathrm{C}$, but the corrosion resistance was 
lower than that at $800^{\circ} \mathrm{C}{ }^{[152]}$. Phase transformation studies of $\mathrm{Ni}-\mathrm{W}-\mathrm{P}-\mathrm{Al}_{2} \mathrm{O}_{3}$ showed that composite coatings exhibited better thermal stability than the plain Ni-W-P deposits ${ }^{[134]}$. Bozzini et al. ${ }^{[154]}$ reported that electroless Ni-P-B 4 C in the as-deposit condition exhibited a strong dependence of magnetic susceptibility on the applied magnetic field due to its larger structural inhomogeneity when compared to plain Ni-P deposit. Nevertheless, after crystallization, plain Ni-P deposits became homogeneous and attain ferromagnetic nature, whereas composite coatings preserved field dependence and exhibited typical super paramagnetic in nature. The difference in magnetic behavior between these coatings is due to the $\mathrm{B}_{4} \mathrm{C}(25 \mathrm{vol} . \%)$ in the coating act as main reason for the nickel phase precipitation.

\subsection{Applications}

The main application of electroless composite coatings is for machining and finishing tools requiring maximum wear resistance, surface friction coefficient, and hard surface. The applications are as follows.

Ni-P-SiC ( $\sim 50 \mu$ thick) increases the life of molds for plastics, rubber etc., by 15 times. It can protect the accelerated corrosion of abrasion molds in the plastic industry (better than chrome plating), and can be used in automobile components such as reinforced plastic front-end pieces ${ }^{[15,24]}$, and in foundries for reducing wear and helping to release sand cores without breakage from core boxes.

Ni-P-PTFE provides non-stick, non-galling, high dry-lubricity, low friction, good wear and corrosion resistant surfaces. It is used in molds for rubber and plastic components, pumps and valves, butterfly valves for the oil and gas industry, fasteners, precision instrument parts, aluminum air cylinders, carburetor and choke shafts ${ }^{[15]}$. It decreases the leak rate and enables safe operation of the valve for cryogenic applications. There is dry lubrication and low-coefficient of friction in build-up of gummy deposits on the choke shafts. 
Other applications include in chains, lock parts, valves, pistons, piston rings, roller bearings, mining equipment parts and dies.

$\mathrm{Ni}-\mathrm{P}-\mathrm{C}$ is applied to reamers made of highly abrasive aluminum alloys, broaching tools for graphite, valves for viscous rubber masses, thread guides for use in textile machines and friction texturizing discs, slip-less transmission of high rotational speed, yarn brakes, variable gears, friction clutches in the textile industry, and making profiled diamond tools used for micro-finishing screw threads, ball-guiding grooves.

Ni-P-PTFE-SiC has applications for molds, automobile parts and general wear components ${ }^{[129]}$. Ni-W-P- $\mathrm{Al}_{2} \mathrm{O}_{3}$ gives better thermal stability ${ }^{[134]}$. Ni-P- $\mathrm{B}_{4} \mathrm{C}$ has magnetic field application ${ }^{[154]}$. Ni-P-Fe $\mathrm{O}_{4}$ has high temperature oxidation application ${ }^{[152]}$.

\section{Electroless nickel nanocoatings}

Electroless nickel nanocoatings are defined to have either the thickness of the coating or the second phase particles that are dispersed into the Ni-P matrix in the range of nano-level. The feasibility to incorporate the fine second phase (in nano size range) particles such as $\mathrm{SiO}_{2}$, CNT, $\mathrm{ZrO}_{2}-\mathrm{Al}_{2} \mathrm{O}_{3}-\mathrm{Al}_{3} \mathrm{Zr}$, hexaferrites, ferrites, $\mathrm{ZnO}, \mathrm{Al}_{2} \mathrm{O}_{3}-\mathrm{TiO}_{2}$ within a metal/alloy matrix has initiated a new generation of electroless Ni-P nanocomposite coatings. In the last ten years, many researchers have synthesized many electroless Ni-P nanocomposite coatings. Among them, the combinations that have received considerable attention are $\mathrm{SiC}^{[128]}, \mathrm{CeO}_{2}$, $\mathrm{TiO}_{2}{ }^{[150-151]}, \mathrm{Al}_{2} \mathrm{O}_{3}, \mathrm{Zn}_{3}\left(\mathrm{PO}_{4}\right)_{2}{ }^{[155]}, \mathrm{ZnSnO}_{3}, \mathrm{ZnSiO}_{3}{ }^{[155]}$, single wall carbon nano tubes (SWCNTs) ${ }^{[156]}$, and nanometer diamond (ND) ${ }^{[135]}$. In addition to this, either the electroless $\mathrm{Ni}-\mathrm{P}$ deposition layer at nano level or on the nano size particles is also termed as electroless Ni-P nanocoatings. 


\subsection{Electroless Ni-P nanocomposite coatings}

Electroless Ni-P deposit incorporated with nano-diamond particles was prepared and the mechanism is described ${ }^{[135]}$. Xiang et al. ${ }^{[108]}$ reported that the nanosized diamond particles (0.52-2.21 wt.\%) in the electroless Ni-P matrix changed the surface from bright and smooth to foggy and rough with nodular surface. In another study, Ni-P composite coatings were obtained by incorporating two kinds of particles, $\mathrm{SiC}$ and $\mathrm{Si}_{3} \mathrm{~N}_{4}$, to analyze the influence of the type of particle both on the co-deposition process and on the coating properties (particles size ranging from $30 \mathrm{~nm}$ to $2 \mu \mathrm{m}$ ). It was observed that the growth mechanism of the metallic matrix was much more modified by the nano-particles than by the micron-sized particles ${ }^{[157]}$.

An alkaline bath with in-situ co-precipitation reaction has been prepared successfully to deposit Ni-P- $\mathrm{ZrO}_{2} / \mathrm{Al}_{2} \mathrm{O}_{3} / \mathrm{Al}_{3} \mathrm{Zr}$ electroless coatings on three different substrate materials, commercial aluminum, low carbon steel and carbon fabric ${ }^{[158]}$. Second phase nano size (80 $\mathrm{nm}) \mathrm{Al}_{2} \mathrm{O}_{3}$ particles incorporated in Ni-P matrix were prepared and studied ${ }^{[22]}$. In addition to this, influence of particle size on the microstructure, hardness and corrosion resistance of electroless Ni-P- $\mathrm{Al}_{2} \mathrm{O}_{3}$ composite coatings with the size of $50 \mathrm{~nm}, 0.3 \mu \mathrm{m}$ and $1 \mu \mathrm{m}$ has been studied. Agarwala prepared to incorporate the nano barium hexaferrites $\left(\mathrm{BaZn}_{2-\mathrm{y}} \mathrm{Co}_{\mathrm{y}} \mathrm{Fe}_{16} \mathrm{O}_{27}\right)$ into electroless Ni-P matrix as barium hexaferrite is an important magnetic material, widely applied as permanent magnet, magnetic recording media and microwave absorbers. The result suggests that this electroless $\mathrm{Ni}-\mathrm{P}$ nanocomposite coating has good microwave absorption properties ${ }^{[159]}$.

Dong et al. reported that the $\mathrm{SiO}_{2}$ nanoparticles were capable of significantly improving the mechanical properties of electroless $\mathrm{Ni}-\mathrm{P}$ coating, increasing the microhardness (after $\sim 400^{\circ} \mathrm{C}$ treatment) and wear resistance ${ }^{[132]}$. The amount of $\mathrm{SiO}_{2}(2$ wt.\%) nano-particles ( $20 \mathrm{~nm}$ in size) co-deposited in the Ni-P (8 wt.\%) matrix improved the 
corrosion resistance of coatings in salty atmosphere ${ }^{[160]}$. Electroless Ni-P deposit with inorganic fullurene- $\mathrm{WS}_{2}$ nanoparticles has increased wear resistance under oil lubricated conditions, better than Ni-P, Ni-P-2H-WS 2 and Ni-P graphite deposits. This is due to their ability to serve as spacers between the asperities of two mating metal surfaces ${ }^{[141]}$.

Carbon nanotubes (CNT) (12 vol.\%), when incorporated in an electroless Ni-P matrix, increase the wear resistance in both as-plated and heat-treated conditions ${ }^{[161]}$, better than that of electroless Ni-P-SiC and Ni-P-graphite deposits. CNT provides a low coefficient of friction, when incorporated in the electroless Ni-P matrix ${ }^{[112,141]}$. Carbon nanotubes, which possess unique topological hollow tubular structure, are the most typical one-dimensional nanomaterial in the order of micrometers in length and nanometers in diameter. They have many practical and potential applications due to their outstanding physical and electrical properties. The Ni-P-CNT composite coatings were fabricated successfully from a suspension of CNT in an electroless bath ${ }^{[156]}$. It was found that Ni-P-CNT has significantly improved electrochemical characteristics. Moreover, these CNTs can be impregnated into very small pores in the porous Ni-matrix to make the passive film more compact and stable. The excellent corrosion resistance and high microhardness of these Ni-P-CNT composite coatings will have wide applications in modern electronic industry. Ang et al. attempted to decorate CNTs using electroless plating synthesis ${ }^{[162]}$. In their route, the first step was to activate the CNTs with Pd-Sn catalytic nuclei via a single-step activation approach. Such activated nanotubes were used as precursors for obtaining nickel and palladium decorated nanotubes via electroless plating. Activation of the nanotube surfaces promoted specific deposition of the metals on the catalytic tube surfaces. As a result, CNTs densely coated with metal nanoparticles were obtained with reduced metal deposition in the reaction solution. Nevertheless, this method needs several steps to decorate the CNTs ${ }^{[162]}$. 


\subsection{Electroless Ni-P nanocoatings}

Electroless deposition in fabricating ultra thin void-free and pore-free electroless coatings on micro, meso and nano sized particles is a new area in nanotechnology. This technology allows obtaining nanostructure composite materials and coatings with the specified properties. It allows producing photo masks and micro devices with nanosized adjacent elements of various thicknesses made of various materials. This technique makes the functional capability of the device and this was found much more advantageous than expensive methods such as e-beam and x-ray lithography ${ }^{[163]}$.

\subsubsection{Electroless nano-nickel particles, dots}

Monodispersed and uniform Ni nanoparticles, in particular, have become the focus of intensive research due to their potential applications in high-density data storage and medical diagnosis ${ }^{[164]}$. Such particles with $\sim 30 \mathrm{~nm}$ diameter were successfully prepared ${ }^{[165]}$. The $\mathrm{Ni}(\mathrm{OH})_{2}$ colloid was used as a Ni source and a $\mathrm{H}_{2} \mathrm{O} / \mathrm{EG}$ mixing solution was used as the solvent, whereas the presence of trace concentrations of EDTA is necessary for the uniformity of the synthesized Ni nanoparticles. This process can be extended to prepare other metallic nanoparticles such as $\mathrm{Cu}, \mathrm{Co}$, and Ag. In another research, Chen et al. reported a method to deposit electroless Ni-P on SiC nanoparticles $(\sim 70 \mathrm{~nm})$. This method is simple and inexpensive and furthermore, it may be used to prepare a wide variety of nanoparticles ${ }^{[166]}$. Motivated by the quest for high-density memory, Osaka et al. used electroless method to deposit $\mathrm{Ni}$ particles on $\mathrm{Si}^{[167]}$. The displacement reaction is effected in the absence of fluoride ions, and hence, a thick oxide layer is present at the Ni nanodot-Si interface. Subsequent to the nucleation of the metallic Ni dots, the substrate is transferred to an electroless Ni-P bath to complete the nanodots' growth. Furthermore, Takano et al. ${ }^{[168]}$ and Niwa et al. ${ }^{[169]}$ developed an electroless deposition process in aqueous alkaline solutions for 
nano nickel plating on Si surfaces. This process was applied for the selective Ni deposition on patterned Si substrates. This was followed by immersion in a hypophosphite-based bath for further growth by the electroless deposition.

\subsubsection{Electroless nano-nickel tubes, arrays, wires, channels}

Interesting properties of magnetic metal nanotubes have aggravated their use in nanomedicine, high-density magnetic recording media and sensing devices. As a recent finding, nanotube arrays that are closed on one end can be utilized for drug delivery applications ${ }^{[170]}$. The end-closed NiCoFe-B nanotubes are deposited on pre-polished anodized aluminum foil by electroless process. Results show the formation of end-closed nanotubes with the dimension of $0.1-0.13 \mu \mathrm{m}$ in outside diameter, which is determined by the pore size of the porous anodic aluminum oxide template, and about $15 \mathrm{~nm}$ in thickness of tube walls ${ }^{[171]}$. Materials that exhibit both antiferromagnetism (AFM) and ferromagnetism (FM) in close proximity are interesting for understanding both the fundamental magnetic interactions and their potential application in new electronic devices. Lo et al. [172] investigated the magnetic properties of $\mathrm{Ni}$ and $\mathrm{Ni}-\mathrm{NiO}$ core-shell nano-arrays, aimed at understanding how the $\mathrm{NiO}$ shell influenced the entire array. The results show that though the $\mathrm{NiO}$ is only $\sim 10 \mathrm{~nm}$, its AFM strength can screen the inner Ni-FM and cause the magnetic properties of entire array to differ greatly from those of a reference Ni nano-array. Yuan et al.

${ }^{\text {[72] }}$ succeeded in fabricating large-scale and uniform electroless Ni-W-P alloy nanowire arrays in an anodic alumina membrane for the purpose of ultra-high-density magnetic recording. In another research, a promising new technique is called the electroless nanowire deposition on micropatterned substrates (ENDOM) ${ }^{[173]}$. This ENDOM is generally applicable to the preparation of metallic, semiconducting, and even insulating nanowires on technologically relevant substrates, is inexpensive, and can achieve high growth rates. The 
width of the nanowires can be varied from 0.2 to $1 \mu \mathrm{m}$ and the height can be varied from 7 to $20 \mathrm{~nm}$, by controlling the deposition time. Metallic nano-porous materials (MNMs) were fabricated by using nanoporous polymer with gyroid nanochannels as a template for the modified electroless plating. Those MNMs with the nature of porous metals and the unique material characteristics of well-ordered nanostructures would exhibit interesting photonic properties for novel applications including enhanced plasmonic behavior, photonic crystals, and metamaterials. This new approach for hybridization provides a precisely controlled method to fabricate nanohybrids and MNMs ${ }^{[174]}$.

\subsubsection{Electroless nano-nickel on CNT and SAM layers}

The electroless Ni-P layers have been preferred for an increasing number of CNT applications in recent years. The one-dimensional SWCNTs with continuous and dense coating layer have been successfully synthesized by an electroless deposition process (thickness $\sim 20 \mathrm{~nm})^{[175]}$. Seidel et al. have developed a very simple method to grow in-situ contacted SWCNTs by means of a metal multilayer system consisting of an electrode metal, an $\mathrm{Al}$ separation layer, and the active catalyst. This presents an easy method for the fabrication of large numbers of simultaneously contacted SWCNTs, a prerequisite for the integration of SWCNTs into nanoelectronic devices or sensors ${ }^{[176]}$, without e-beam lithography. Carbon nanofibers (CNFs) were fabricated on a Ni-P alloy catalyst deposited on a Si substrate in a microwave heating chemical vapor deposition system with methane gas at $650^{\circ} \mathrm{C}$. The nanosized clusters on the clustered surface of the Ni-P alloy catalyst film directly provided the nucleation sites for CNFs without any pre-treatment before the growth of the CNFs. The CNFs grown on the Ni-P alloy catalyst showed random orientation, and were composed of parallel graphite planes with defects tilted from their axis. Measurement indicated that the Ni-P catalyzed CNFs exhibited excellent field emission properties ${ }^{[177]}$. 
Additionally, one can pattern an organosilane self-assembled monolayer (SAM) with photons via a photomask ${ }^{[178]}$. Sugimura et al. demonstrated that they could electrolessly plate $\mathrm{Ni}$ in the exposed regions, followed by an additional etch with plasma in the exposed regions. Low energy electrons ( $\sim 50 \mathrm{eV})$ have also been used to pattern trimethylsilyl SAMs. The irradiated regions were destroyed in striped patterns, and an amine-terminated silane was backfilled in those regions ${ }^{[179]}$. An excellent alternative to vacuum methods is adsorption of noble metal cations that can be reduced to the zero valent state, which in turn catalyze electroless deposition of metals. To this end, silanes should contain groups that can be photochemically altered to allow optical or UV lithography. For example, aromatic trichlorosilanes can react with substrates, while their functional groups such as chloromethyl can bind $\operatorname{Pd}(\mathrm{II})$ complexes. The groups can be photochemically oxidized to oxygencontaining groups that do not bind Pd(II). Reduction and immersion in an electroless metallization bath create micropatterns of metal, e.g. nickel, with sharp boundaries on top of the silane layer ${ }^{[180]}$.

\subsubsection{Electroless nano-nickel on bio-molecular surfaces}

Virus particles, so-called virions, consist of a nuclei acid strand and a protein cage or tube that is made up from a large number of identical proteins. Similar arguments apply also for bio-mineralizations, e.g. of $\mathrm{TiO}_{2}$ on Tobacco Mosaic Virions (TMV) ${ }^{[181]}$. A similar scenario operates for the electroless deposition of Ni on TMV. For this example, one can assume that phosphate attaches to several positively charged pockets on the exterior viral surface. Now, on Ni nuclei, the growth is autocatalytic. The produced structure is a nickel tube with a well-defined tubular hole of $18 \mathrm{~nm}$ diameter. The coalescence leads to rather large $(>10 \mathrm{~nm})$ structures, a problem encountered with all biological rods and tubes, and especially well known for DNA and TMV. Here the attachment is purely mechanical, and for this reason the clusters have to grow fast and coalesce to coat the virion completely. From the 
above, it is quite obvious that a surface science as for crystalline inorganic surfaces does not (yet) exist for bio-molecular surfaces, and that it would be very much based on organic chemistry of the functional groups ${ }^{[182]}$.

\section{Plating on difficult substrate and waste treatment}

A number of technologies are available for coating difficult substrate, including magnesium, aluminum, and their alloys, in addition to plastic, glass and ceramics. These include electrochemical plating, conversion coatings, anodizing, hydride coatings, organic coatings and vapor-phase processes. Each of these have its own application, where and how they need to be used. Among these, electroless plating is a promising one.

\subsection{Plating onto plastics, polymers and ceramics}

One advantage of using plastics is that moldings of complex shape can be made very cheap, accurately and with high quality surface finish. It has lower density than metals and has good strength-to-weight ratio. Plated plastics compete with plated brass, zinc alloy diecastings and anodized aluminum. An application for the automotive industry is the production of reflective surfaces for the exterior mirrors, where plastic mirrors can be molded accurately to zero tolerance and are less susceptible to damage. Electroless plating on plastics is now a well-known technology. Plating on plastics (POP) has been developed and widely used in manufacturing printed circuit boards (PCBs) and automobile parts, and in the electromagnetic interference shielding application ${ }^{[13,24,183]}$. In general, the processes such as etching, neutralization, activation, and acceleration are needed before the plating starts. The concept for activation metal needed before plating is that a noble metal ion can be reduced and deposited onto a less noble metal substrate based on the simple displacement chemistry. The pre-treatment for plastics other than acrylonitrile-butadiene-styrene (ABS) system can be 
exactly the same as for ABS, the same chromic acid etching being suitable for both plastics. However, it needs a specific neutralizer subsequent to this etching.

The following flow explains the process sequence for preparing ABS plastics to be electro/electroless deposited: etching bath (concentrated sulfuric acid; chromic acid; 3-9 min at $65^{\circ} \mathrm{C}$ ) $\rightarrow$ diluted $\mathrm{HCl}$ dip $\rightarrow$ activation bath (palladium chloride; stannous chloride; stannic chloride; concentrated $\mathrm{HCl}$; 3-6 min at $\left.30^{\circ} \mathrm{C}\right) \rightarrow$ diluted $\mathrm{HCl}$ dip $\rightarrow$ electroless copper or nickel ${ }^{[184]}$. The acid etching process of ABS is probably the most crucial process and the composition of the solution is important, which is directly related to adhesion properties of metal coated on it. The Al-C enamel pastes were coated onto ABS plastic to create Al-seeded surfaces onto which $\mathrm{Cu} / \mathrm{Ni}$ could be readily deposited through a simple electroless procedure, converting the non-conductive plastic surface into conductive ${ }^{[184]}$.

A novel surface activation process has been proposed for plating onto ABS plastics by employing biopolymer chitosan ${ }^{[185-186]}$. This proposed method enhanced the adhesive strength of plating layer and substrate by chemical sorption instead of the physical sorption in the conventional sensitizing-activation method. In addition, etching solution without chromium was employed to modify the surface of ABS by an eco-friendly manner. The resistivity and anti-oxidization of conductive fillers were important factors for electromagnetic interference shielding composites. Tang et al. developed recently a novel palladium-free and environmentally friendly surface activation process for $\mathrm{Ni}$ electroless plating. In this study, the activation was carried out by immobilizing $\mathrm{Ni}$ nanoparticles as catalyst site on the ABS plastic surface and it is a cost effective activation method ${ }^{[187]}$. Garcia et al. ${ }^{[188]}$ developed a simple 3D amino-induced electroless plating process, combined with a direct patterning method, allowing the production of selective metal patterns with good electrical and mechanical properties onto flexible and transparent poly(ethylene terephtalate) (PET) sheets. Such a process could be an excellent alternative method for the cost-effective 
fabrication of large-area plastic electronic devices. Furthermore, in the conventional activation processes, noble metal palladium is usually employed as the catalyst sites to initiate the electroless nickel plating. The cost of palladium has increased in recent years, which makes the price for electroless deposit rise. Thus, it is very important to develop a cost effective activation techniques. A new, efficient, palladium- and etchant-free process for the electroless nickel plating of PET fabric has been developed. The nickel coating obtained in this palladium-free process can pass through ultrasonic washing challenge, and shows excellent adhesion with the PET substrate ${ }^{[189]}$.

Electromagnetic interference (EMI) shielding effectiveness (SE) of single-layer or double-layer electroless metals, such as nickel/phosphorus-pure nickel (NiP-Ni), Ni-NiP, $\mathrm{NiP}-\mathrm{Cu}, \mathrm{Ni}-\mathrm{Cu}$, coated carbon fiber reinforced ABS composites was investigated. Results suggest ${ }^{[190]}$ that electroless copper-coated carbon fibers (ECCF) in ABS composite showed a low EMI SE (37 dBm) among those electroless metals coated carbon fiber-reinforced ABS composites. The double layer electroless metals on the conductive fillers obtained by electroless possess better anti-oxidization, and provide suitable protection for the conductive fillers and hence, the ECCF ABS composite has improved shielding effectively, this value reaching up to $65 \mathrm{dBm}$.

Charbonnier et al. describe how polymer surfaces can be modified by adsorbing noble metal complexes. Contacting such surfaces with an electroless deposition bath will reduce the complexes, and clusters form. These clusters are very good nucleation centers for electroless deposition. The general procedure can be used for the metallization of plastics ${ }^{[191]}$. More complex structures are polymer brushes. They can be grafted on $\mathrm{H}$-terminated $\mathrm{Si}$, and be terminated with viologen groups. Their redox chemistry was used to reduce noble metal cations to metal clusters ${ }^{[192]}$. Similarly, polyaniline can coat silane layers on glass and reduce the metal cations. Well-dispersed clusters are supposed to form in the polymer layer, and 
again electroless deposition can easily be initiated on these clusters ${ }^{[193]}$. Systems of this type can be addressed as precursors or first stages in the production of metal over layers on polymers, e.g. by electroless deposition ${ }^{[194]}$. Note that complex deposition processes such as electroless deposition can cause complex situations, e.g. large clusters adsorbed on, and smaller clusters located below the surface ${ }^{[195-196]}$. In a recent study, Kimura et al. ${ }^{[197]}$ demonstrated a simple route to depositing nickel layer patterns using photocross-linked polymer thin films containing palladium catalysts, which can be used as adhesive interlayers for fabrication of nickel patterns on glass and plastic substrates. This kind of direct patterning metallic layers onto insulating substrates has a great potential for fabricating micro/nano devices.

A recent study shows the electroless coating of $\mathrm{Ni}-\mathrm{P}$ onto boron carbide $\left(\mathrm{B}_{4} \mathrm{C}\right)$ ceramic particles with average particle sizes of 93 and $32 \mu \mathrm{m}$, where the substrate $\mathrm{B}_{4} \mathrm{C}$ is one of the super-hard materials with its hardness $\left(2900-3900 \mathrm{~kg} / \mathrm{mm}^{2}\right)$ just below that of diamond [198].

\subsection{Plating onto aluminum}

Aluminum alloys constitute a very important class of engineering materials widely employed in the aircraft and aerospace industry for the manufacturing of different parts and components due to their high strength-to-density ratio and being the second cheapest of all commercially important metals after magnesium. Moreover, all aluminum alloys are extremely susceptible to the formation of instantaneous oxide layer and results in an unattractive appearance with inferior mechanical properties. Special pre-treatments sequences are necessary in order to make them suitable to electro/electroless deposition with adherent coatings. Electroless nickel is deposited on a wide range of aluminum alloys, especially for electrical components, so the soldered connections are to be made with a suitable metal such as tin. Metals other than nickel are also being deposited onto aluminum substrate for certain 
applications. The oxide film present on aluminum prevents solder from adhering to its surface. Gold is also deposited on aluminum for some electrical components, such as contacts and lead/tin alloy deposits for some bearing surfaces. Most of the metals for plating directly onto aluminum have involved the use of specialized zinc plating bath and meets many challenges in processing. However, the electroless plating on aluminum alloys is preferred. The most widely used pre-treatment for aluminum, which is widely acceptable today are $\mathrm{Zn}$ (zincate), Ni strike and absorbed hypophosphite (HP). Recently, these pre-treatments effects have been researched for wear properties ${ }^{[199]}$ and corrosion ${ }^{[200]}$. The process includes grinding $\rightarrow$ degreasing bath $\rightarrow$ etching bath $\rightarrow$ pre-treatment (zincate; Ni-strike; absorbed HP adlayer) $\rightarrow$ electroless nickel depositions ${ }^{[200]}$.

Recent research work suggests that hypophosphite absorbed adlayer is promising for corrosion resistance and $\mathrm{Ni}$ strike is promising for wear resistance compared to conventional Zn immersion ${ }^{[199-200]}$. It further shows that high phosphorus plating improves the fatigue behavior of 7075 aluminum alloy ${ }^{[201]}$. Coatings containing $10 \%$ or more phosphorus are compressively stressed on steel and tend to resist cracking, which may be an explanation for the improvement of the fatigue behavior of the aluminum alloy here. Heat-treatment causes a decrease in fatigue resistance in general.

\subsection{Plating onto magnesium}

Magnesium presents even more problems than does aluminum since it oxidizes far more readily. Magnesium is also prone to galvanic corrosion because most other metals have a more noble electrochemical potential and it has high reactivity. Generally, surface modification treatments such as chemical conversion coatings, anodizing, electroless nickel deposition, nickel/polymer electro-deposition, PVD of high purity magnesium and nitrogen ion implantation are widely used to improve the corrosion resistance of $\mathrm{Mg}^{[202]}$. More care must be taken to develop non-traditional plating baths since magnesium reacts violently with 
most acids and dissolves in acid media. Electrolytic contact with another metal can cause the formation of local corrosion cells on the surface leading to pitting. Therefore, the metal coating must be pore free, as otherwise the corrosion rate will increase ${ }^{[202]}$. The minimum coating thickness of $50 \mu \mathrm{m}$ has been suggested to ensure pore-free coatings for outdoor use. Another challenge in the plating of magnesium is that the desirable quality of the metal coating depends on the alloy being plated. This requires the development of different pretreatment processes for different alloys. Alloys are especially difficult to plate because intermetallic species such as $\mathrm{Mg}_{\mathrm{x}} \mathrm{Al}_{\mathrm{y}}$ are formed at the grain boundaries, resulting in a nonuniform surface potential across the substrate, and therefore further complicating the plating process.

There are two preferred pre-treatment for magnesium alloys, zinc immersion and electroless nickel from fluoride containing bath, for further metallic plating. Electroless nickel is plated directly onto magnesium alloy AZ91 die castings, developed by Sakata ${ }^{[203]}$. The author states that uniform, adherent coatings were obtained. The process flow is mechanical polish $\rightarrow$ degrease $\rightarrow$ alkaline etching $\rightarrow$ acid activation $\rightarrow$ alkaline activation $\rightarrow$ alkaline electroless nickel strike $\rightarrow$ acid electroless nickel plating. This process has been criticized ${ }^{[204]}$ for using an acid electroless nickel treatment that accelerates the corrosion of the underlying magnesium if any pores are present in the nickel strike layer. A simpler process has been processed by PMD (UK) ${ }^{[205-206]}$. The fluoride conditioning was found to remove toxic chromium and control the deposition rate by passivating the surface and inhibit corrosion of the substrate during plating. In addition, report suggests strong adhesion of the nickel film. However, the bath life is too short. The addition of a complexing agent, glycine, increases the stability of the plating bath. The process flow is mechanical polish $\rightarrow$ degrease $\rightarrow$ alkaline clean $\rightarrow$ acid pickle $\rightarrow$ fluoride activation $\rightarrow$ electroless nickel plating. 
Toshinobu et al. proposed a process involving treatment of the sample with a chemical etching solution containing pyrophosphate, nitrate and sulfate, avoiding the use of toxic chromium ions ${ }^{[207]}$. The plated samples achieved have high adhesion and corrosion resistance and have been shown to not corrode magnesium. The process flow is mechanical polish $\rightarrow$ chemical etching $\rightarrow$ fluoride treatment $\rightarrow$ neutralization $\rightarrow$ electroless nickel plating.

Nickel and gold plating on magnesium have both proven useful for space applications. Successful gold plating has been achieved using the following sequence on magnesium/lithium alloys ${ }^{[208]}$ : mechanical polish $\rightarrow$ degrease $\rightarrow$ alkaline cleaning $\rightarrow$ chromic acid pickle $\rightarrow$ electroplated nickel $\rightarrow$ electroless nickel $\rightarrow$ gold strike $\rightarrow$ electroplated gold.

The initial electrodeposited nickel film is porous but acts as an activator for uniform electroless nickel plating and proves to be a suitable basis for gold plating. A zinc immersion pre-treatment ${ }^{[209]}$ process followed by electroless nickel plating and subsequent gold plating was found to give good mechanical, thermal and optical properties on AZ31 magnesium alloy. The homogeneous interlayer zinc followed by a hard porous micro cracked electroless nickel film with a final gold layer was crack-free. Some poor quality of zinc deposits was attributed to coarse, non-uniform substrate grains with widely varying surface chemical composition. The pre-treatment process was altered to create a uniform surface for nickel plating. An AC 5 $\mathrm{V}$ electrolytic treatment was added during the fluoride activation stage. The process flow becomes mechanical polish $\rightarrow$ acid pickle $\rightarrow \mathrm{HF}$ dip $\rightarrow$ AC electrolytic treatment $\rightarrow$ electroless nickel plating from a fluoride bath $\rightarrow$ nickel electroplating $\rightarrow$ gold electroplating.

The above pretreated coating exceeded its predicted life span of 2 years. This plating method can be applied to objects such as satellite embarking devices. Direct electroless nickel plating on magnesium alloy ZM21 has been shown to produce coatings with good 
mechanical, environmental, optical and soldering properties ${ }^{[210]}$. Electroless can also be used as an intermediate layer for load-carrying capacitor to improve its capacity ${ }^{[211]}$ but there is no report on corrosion studies of this system.

Zhao et al. proposed a novel method to deposit dense copper film on the surface of magnesium alloy by using organic coatings ${ }^{[212]}$. The proposed research indicates that the adhesion between the interlayer and the substrate is very good. In addition, this proposed work can make it possible to plate other metals on the magnesium alloys like silver, nickel and their alloys or other highly active metals. Microstructure and mechanical properties can be improved on magnesium alloy by mechanical attrition ${ }^{[213-215]}$. Their proposed results suggest that an alloyed layer forms at the interface between substrate and Ni-P, resulting in Ni-P coatings with a smooth surface, compact and fine-grained structure and free of pores and cracks. In addition, the phase has been transformed from amorphous to crystallized state. Adhesion, hardness and corrosion resistance can be improved effectively.

\subsection{Waste water treatment}

Electroplating/electroless processes are major industrial contributors of heavy metal effluents into the environment as only $30-40 \%$ of all metals used in plating processes are effectively utilized (plated on the substrate) ${ }^{[60,216]}$. A few metals that are generally used in electroless/electroplating are copper, nickel, zinc, chromium. Water is used in the electrolytic bath, washing and rinsing of the electroless/electroplated articles. Of these waste streams, waste pickle liquor from the pickling units and bleed streams from the electroplating units are of major concern due to the presence of high metals and acid contents which renders them highly corrosive and polluting in nature. Other pollutants such as cyanide, $\mathrm{Cu}$ (II), Ni (II), Fe (II), Fe (III), Cr (VI) and certain organic compounds such as degreasing solvents are also present in metal finishing waste waters which are highly toxic even at low concentration in water $^{[217-218]}$. There are various methods for the treatment of waste pickle liquors. They are 
pyrohydrolysis, neutralization/precipitation, crystallization, thermal decomposition, electrolytic precipitation/deposition, ion-exchange technique/acid retardation method, electrodialysis/membrane separation/diffusion dialysis, solvent extraction ${ }^{[60]}$. The commonly used method of lime neutralization of the acid content and precipitation of the metal content from such waste streams leads to the loss of acid and metal values along with the generation of a huge amount of sludge due to the precipitation of metals as hydroxides. However, this treatment method of sludge disposal burden is main drawback. Hence, the concept of recycling/recovery/reuse of these wastes is stressed upon so as to convert these streams as a secondary source of acid and metal content in it. Hydrometallurgical processes of solvent extraction method are among the promising ones.

\subsubsection{Plating tank}

During electroless plating, tanks also get plated; this is called plate-out. Plate-out is removed once in 3-5 days for high-volume work. Waste treatment uses steel wool as substrate for Ni deposition in spent bath, and plated steel wool is rinsed, dried, and sold in the market for decorative products. With plastic tanks, plate-out is dissolved in nitric acid and rinsed. With steel tanks, the tanks are passivated with nitric acid before plating, and tank body is maintained at a slightly anodic potential by application of a voltage between tank and a small cathode. Continuous plating depletes the bath of metal and other chemicals, and these must be replenished. Generally, plating bath needs to be replenished more frequently in electroless plating than in electroplating. The total amount of $\mathrm{Ni}$ replenished is measured in units of cycles or metal turnover. A cycle is defined as the ratio of total quantity of $\mathrm{Ni}$ replenishment added to the total quantity of $\mathrm{Ni}$ present in bath. Automatic control of bath composition is achieved by the use of photometric cells that detect changes in $\mathrm{Ni}$ concentration by variation of solution light transmittance. Changes beyond preset limits activate pumps to add to the decreased concentration of the bath. 


\subsubsection{Electroless bath}

Electroless deposition processes have a limited bath life and the problem is more aggravated in the case of magnesium plating due to its high reactivity. An example reported is the process developed by PMD (UK) that is capable of six regenerations, each with a 45min turnover time if a strict replenishment schedule is followed ${ }^{[219]}$. The short lifetime of the baths is a serious limitation from both cost and environmental perspectives. Researchers are needed on increasing the bath life and eliminating toxic chemicals, to create 'green' plating processes for electroless coating, particularly onto difficult substrate using toxic chromium compounds, cyanide compounds and fluoride compounds. Generally, it has limited life due to the formation of reaction byproducts. In acid electroless nickel (hypophosphite-reduced) baths, the added accumulation or concentration of orthophosphate in the solution will eventually decrease the plating rate and deposit quality, initiating bath disposal. Also, the chelators and stabilizers make it difficult to reduce the electroless metal content by alkaline precipitation. Conventional precipitation method to form metal hydroxide or sulfide sludge through continuous or batch treatment involves a multitudinous of $\mathrm{pH}$ adjustment process to convert dissolved metals into solids for de-watering and hazardous disposal. Special attentions have to be placed on waste minimization as the primary step in reducing waste treatment. For examples, ion exchange, reverse osmosis, and electrowinning or electrolytic recovery, which involves electroplates the spent bath into nickel or copper metal onto special cathodes helping to reduce the amount of sulfide or hydroxide hazardous sludge. The final plated metal produced can be reclaimed as scrap metal. Furthermore, waste minimization methods include using steel wool to plate out the electroless bath prior to further waste treatment. Electroplating does not have as much environmental impact due to the relatively long bath life of the plating solutions. However, it cannot achieve uniform coatings on 
complex shapes. Other similar applications concern the removal of phosphite from an electroless nickel bath or the recovery of $\mathrm{HF}$ and $\mathrm{HNO}_{3}$ used to clean stainless steel.

\section{Future scope and conclusion}

This review article outlines the overall aspects of electroless nickel coatings as a whole. In particular, it reviews the methods of formation of electroless nickelphosphorus/boron, polyalloys, composite coatings, nanocoatings and their effect on coating characteristics, applications and their recent developments.

In future, new alloy added with electroless nickel coating may fulfill new benefits and property. Work has to be done on improving the plating of difficult substrates (i.e., aluminum and magnesium) that require thick and eco-friendly coatings for some applications, and lowering the chemical usage and cost. In addition, getting maximum efficiency from the bath is more important in future. Reducing the prices of electroless plating on plastics used for automotive industries and minimizes the bath wastage; greener plating technology will be more attractive.

Electroless nickel composite coatings could have a bright future for wear-resistant or self-lubricating coatings and other special treatments. In future, new composite material may fulfill new benefits and property. With the advent of automatic controllers and more advanced processing technology, polyalloys and composites may become the next frontier of electroless technology. The composite coatings can provide an excellent layer of coating containing nickel and other components to be used for defense and intelligent materials.

The results of electroless nickel nanocoating have shown that the second phase nano particles ( $\mathrm{SiC}, \mathrm{CeO}_{2}, \mathrm{TiO}_{2}, \mathrm{Al}_{2} \mathrm{O}_{3}, \mathrm{CNTs}$, nanometer diamond, etc.) could be incorporated successfully in the Ni-P matrix by electroless plating technique. In addition, it produces the nano-nickel particles, dots, nano-nickel tubes, arrays, wires for various applications. 
Furthermore, nano-nickel can be deposited on CNT, SAM layers and on bio-molecular surface. These electroless nickel based nanocomposite/nanocoatings have gained more attention in research community due to their ability to produce coatings that possess useful physical and mechanical properties.

The properties of electroless nickel coatings are improved continuously by suitable surface treatments (heat, laser, etc.) and the incorporation of various elements (copper, tungsten, etc.) and particles ( $\mathrm{SiC}, \mathrm{TiO}_{2}$, etc.) by the various researchers to suit the various applications. As a concluding remark, the future of electroless plating will depend on the newer requirements and applications, as well as changes in plating technology.

\section{Acknowledgement}

One of our authors (Jothi Sudagar) acknowledges the India-China Cultural Exchange Scholarship Program and Jilin University for financial support.

\section{References}

[1]Brenner A and Riddell G E; Nickel plating on steel by chemical reduction, Journal of Research of the National Bureau of Standards, 1946, Vol 37, p 31-34.

[2]Brenner A and Riddell G; Electroless plating by a process of controlled self continuing reduction, Proc. Amer. Electropl. Soc., 1946, Vol 33, p 16-19.

[3]Brenner A and Riddell G; Proc. Amer. Electropl. Soc., 1947, Vol 34, p 156-159.

[4]Brenner A and Riddell G E; Deposition of nickel and cobalt by chemical reduction, Journal of Research of the National Bureau of Standards, 1947, Vol 39, p 385-395.

[5]Wurtz A; Formation of a cuprous hydride, by the action of hypophosphorus acid on a cupric salt solution, Ann. Chim. Phys., 1844, Vol 11, p 250-252. 
[6]Carraro C, Maboudian R and Magafnin L; Metallization and nanostructuring of semiconductor surfaces by galvanic displacement processes, Surface Science Reports, 2007, Vol 62, p 499-525.

[7]Scholder R and Heckel H; Über Schwermetallphosphide. I. Mitteilung. Einwirkung von hypophosphit auf nickel-und kobaltsalze, Zeitschrift für Anorganische und Allgemeine Chemie, 1931, Vol 198, p 329-351.

[8]Gabe D; Dr. Abner Brenner, Transactions of the Institute of Metal Finishing, 2009, Vol 87, p 229-229.

[9]Gutzeit G; Chemical nickel plating processes and baths therefor, (US Patent 2,822,294 1958).

[10]Wang W, Vora R, Kang E and Neoh K; Electroless plating of copper on fluorinated polyimide films modified by surface graft copolymerization with 1 vinylimidazole and 4 vinylpyridine, Polymer Engineering \& Science, 2004, Vol 44, p 362-375.

[11]Domenech S and Lima E; Electroless plating of nickel-phosphorus on surface-modified poly (ethylene terephthalate) films, Applied Surface Science, 2003, Vol 220, p 238-250.

[12]Huang T C, Wei M C and Chen H I; Preparation of hydrogen-permselective palladiumsilver alloy composite membranes by electroless co-deposition, Separation and Purification Technology, 2003, Vol 32, p 239-245.

[13]Krishnan K H, John S, Srinivasan K, Praveen J, Ganesan M and Kavimani P; An overall aspect of electroless Ni-P depositions-A review article, Metallurgical and Materials Transactions A, 2006, Vol 37, p 1917-1926.

[14]Gawrilov G; Chemical (electroless) nickel plating, (Portcullis Press, Redhill, England, 1979).

[15]Mallory G O and Hajdu J B; Electroless plating: fundamentals and applications, (William Andrew, 1990). 
[16]Gutzeit G; Processes of chemical nickel plating, (US Patent 2,766,138, 1956).

[17]Gutzeit G; Catalytic nickel deposition from aqueous solution. I-IV, Plating and Surface Finishing, 1959, Vol 46, p 1158-1164.

[18]Gutzeit G; An outline of the chemistry involved in the process of catalytic nickel deposition from aqueous solution-Part I, Plating, 1959, Vol 10, p 1158-1161.

[19]Gutzeit G; Kanigen nickel plating, Met. Prog., 1954, Vol 66, p 113-120.

[20]Odekerken J M; Method of electrodepositing a corrosion resistant nickel-chromium coating and product thereof, (US Patent 3,282,810, 1966).

[21]Odekerken J M; Process for coating an object with a bright nickel/chromium coating, (US Patent 3,644,183, 1972).

[22]Agarwala R C, Agarwala V and Sharma R; Electroless Ni-P based nanocoating technology-A review, Synthesis and Reactivity in Inorganic, Metal-Organic and Nano-Metal Chemistry, 2006, Vol 36, p 493-515.

[23]Feldstein N, Lancsek T, Lindsay D and Salerno L; Electroless composite plating, Metals Finishing, 1983, Vol 81, p 35-41.

[24]Balaraju J, Sankara Narayanan T and Seshadri S; Electroless Ni-P composite coatings, Journal of Applied Electrochemistry, 2003, Vol 33, p 807-816.

[25]Sahoo P and Das S K; Tribology of electroless nickel coatings-A review, Materials \& Design, 2011, Vol 32, p 1760-1775.

[26]Agarwala R and Agarwala V; Electroless alloy/composite coatings: A review, Sadhana, 2003, Vol 28, p 475-493.

[27]Li L, An M and Wu G; A new electroless nickel deposition technique to metallise $\mathrm{SiC}_{\mathrm{p}} / \mathrm{Al}$ composites, Surface and Coatings Technology, 2006, Vol 200, p 5102-5112.

[28]Gould A, Boden P and Harris S; Phosphorus distribution in electroless nickel deposits, Surface Technology, 1981, Vol 12, p 93-102. 
[29]Marshall J H; The nickel metal catalyzed decomposition of aqueous hypophosphite solutions, Journal of the Electrochemical Society, 1983, Vol 130, p 369-372.

[30]Bindra P and Roldan J; Mechanisms of electroless metal plating. III. Mixed potential theory and the interdependence of partial reactions, Journal of Applied Electrochemistry, 1987, Vol 17, p 1254-1266.

[31]Brenner A and Riddell G E; Electroless plating comes of age, Metals Finishing, 1954, Vol 52, p 68-76.

[32]Mallory G; Influence of the electroless plating bath on the corrosion resistance of the deposits, Plating, 1974, Vol 61, p 1005-1014.

[33]Vitkavage D and Paunovic M; Maximum rate of the cathodic reaction in electroless copper deposition, Plating and Surface Finishing, 1983, Vol 70, p 48-50.

[34]Lukes R; The mechanism for the autocatalytic reduction of nickel by hypophosphite ion, Plating, 1964, Vol 51, p 969-972.

[35]Henry J R; Electroless (autocatalytic) plating, Metal Finishing, 2007, Vol 105, p 350-360. [36]Lowenheim F A; Electroplating-Fundamentals of surface finishing, ( McGraw-Hill Book Co., New York, 1978).

[37]Guo Z, Keong K G, and Sha W; Crystallisation and phase transformation behaviour of electroless nickel phosphorus platings during continuous heating, Journal of Alloys and Compounds, 2003, Vol 358, p 112-119.

[38]Higgs C; The effect of heat treatment on the structure and hardness of an electrolessly deposited nickel-phosphorus alloy, Electrodeposition and Surface Treatment, 1974, Vol 2, p 315-326.

[39]Thickness of metallic and Inorganic coatings, ASTM designation, 1986, B659-85.

[40]Dini J; Thick nickel deposits of high purity by electroless method, Coronado, 1967, Vol 54, p 385-390. 
[41]Steinmetz P, Alperine S, Friant-costantini A and Josso P; Electroless deposition of pure nickel, palladium and platinum, Surface and Coatings Technology, 1990, Vol 43, p 500-510. [42]Brown R J C, Brewer P J and Milton M J T; The physical and chemical properties of electroless nickel-phosphorus alloys and low reflectance nickel-phosphorus black surfaces, J. Mater. Chem., 2002, Vol 12, p 2749-2754.

[43]Uma Rani R, Sharma A, Minu C, Poornima G and Tejaswi S; Studies on black electroless nickel coatings on titanium alloys for spacecraft thermal control applications, Journal of Applied Electrochemistry, 2010, Vol 40, p 333-339.

[44]Papini M; Chemical, structural and optical characterization of Ni-P chemical conversion coatings for photothermal absorption of solar energy, Solar Energy Materials, 1986, Vol 13, p 233-265.

[45]Johnson C; Black electroless nickel surface morphologies with extremely high light absorption capacity, Metal Finishing, 1980, Vol 78, p 21-24.

[46]Kumar S, Malhotra L and Chopra K; Low cost electroless nickel black coatings for photothermal conversion, Solar Energy Materials, 1980, Vol 3, p 519-532.

[47]Gad M R and El-magd A; Additives for electroless nickel alloy coating processes, Metal Finishing, 2001, Vol 99, p 77-83.

[48]Yin $\mathrm{X}$, Hong $\mathrm{L}$ and Chen $\mathrm{B}$; Role of a $\mathrm{Pb}^{2+}$ stabilizer in the electroless nickel plating system: A theoretical exploration, Journal of Physical Chemistry B, 2004, Vol 108, p 1091910929.

[49]Xiao Z, Wang W, Ye L, Sha Y and Tu S; Effect of $\mathrm{Cd}^{2+}$ as a stabilizer in the electroless nickel plating system, Surface and Coatings Technology, 2008, Vol 202, p 5008-5011.

[50]Cheong W, Luan B L and Shoesmith D W; The effects of stabilizers on the bath stability of electroless Ni deposition and the deposit, Applied Surface Science, 2004, Vol 229, p 282300. 
[51]Liu H P, Li N, Bi S F, Li D Y and Zou Z L; Effect of organic additives on the corrosion resistance properties of electroless nickel deposits, Thin Solid Films, 2008, Vol 516, p 18831889.

[52]Cheong W J, Luan B L and Shoesmith D W; Protective coating on Mg AZ91D alloy-The effect of electroless nickel (EN) bath stabilizers on corrosion behaviour of Ni-P deposit, Corrosion Science, 2007, Vol 49, p 1777-1798.

[53]Chen B H, Hong L, Ma Y and Ko T M; Effects of surfactants in an electroless nickelplating bath on the properties of Ni-P alloy deposits, Industrial \& Engineering Chemistry Research, 2002, Vol 41, p 2668-2678.

[54]Ashassi-Sorkhabi H, Moradi-Haghighi M and Hosseini M; Effect of rare earth (Ce, La) compounds in the electroless bath on the plating rate, bath stability and microstructure of the nickel-phosphorus deposits, Surface and Coatings Technology, 2008, Vol 202, p 1615-1620. [55]Ger M D, Sung Y and Ou J L; A novel process of electroless Ni-P plating by nonisothermal method, Materials Chemistry and Physics, 2005, Vol 89, p 383-389.

[56]Srinivasan K and John S; Electroless nickel deposition from methane sulfonate bath, Journal of Alloys and Compounds, 2009, Vol 486, p 447-450.

[57]Monir Vaghefi S Y and Monir Vaghefi S M; Prediction of phosphorus content of electroless nickel-phosphorus coatings using artificial neural network modeling, Neural Computing \& Applications, 2011, Vol 20, p 1055-1060.

[58]Vaghefi M, Yousef S and Mahmoud S; A novel multilayer neural network model for heat treatment of electroless Ni-P coatings, The International Joint Conference on Neural Networks (IJCNN), 2011, p 3036-3041.

[59]Bedingfield P B, Lewis D, Datta P, Gray J and Wells P; Studies of eelctroless nickelboron alloy coatings, Transactions of the Institute of Metal Finishing, 1992, Vol 70, p 19-23. 
[60]Agrawal A and Sahu. K; An overview of the recovery of acid from spent acidic solutions from steel and electroplating industries, Journal of Hazardous Materials, 2009, Vol 171, p 6175.

[61]Dervos C, Novakovic J and Vassiliou P; Vacuum heat treatment of electroless Ni-B coatings, Materials Letters, 2004, Vol 58, p 619-623.

[62]Kanta A F, Vitry V and Delaunois F; Effect of thermochemical and heat treatments on electroless nickel-boron, Materials Letters, 2009, Vol 63, p 2662-2665.

[63]Kanta A F, Vitry V and Delaunois F; Wear and corrosion resistance behaviours of autocatalytic electroless plating, Journal of Alloys and Compounds, 2009, Vol 486, p L21L23.

[64]Vitry V, Kanta A F and Delaunois F; Mechanical and wear characterization of electroless nickel-boron coatings, Surface and Coatings Technology, 2011, Vol 206, p 1879-1885.

[65]Wang Y, Xiao C and Deng Z; Structure and corrosion resistance of electroless Ni-Cu-P, Plating and Surface Finishing, 1992, Vol 79, p 57-59.

[66]Gorbunova K, Nikiforova A and Sadkov G. In: Mel'nikova M M, Electrochemistry, 1966. [67]Wang L, Zhao L, Zhang B, Hu W, Shu X, Sheng X and Fang Z; Crystallization study of electroless Fe-Sn-B amorphous alloy deposits, Journal of Alloys and Compounds, 1999, Vol 287, p 234-238.

[68]Georgieva J and Armyanov S; Electroless deposition and some properties of Ni-Cu-P and Ni-Sn-P coatings, Journal of Solid State Electrochemistry, 2007, Vol 11, p 869-876.

[69]Liu Y and Zhao Q; Study of electroless Ni-Cu-P coatings and their anti-corrosion properties, Applied Surface Science, 2004, Vol 228, p 57-62.

[70]Liu G, Yang L, Wang L, Wang S, Chongyang L and Wang J; Corrosion behavior of electroless deposited $\mathrm{Ni}-\mathrm{Cu}-\mathrm{P}$ coating in flue gas condensate, Surface and Coatings Technology, 2010, Vol 204, p 3382-3386. 
[71]Valova E, Georgieva J, Armyanov S, Avramova I, Dille J, Kubova O and DelplanckeOgletree M P; Corrosion behavior of hybrid coatings: Electroless Ni-Cu-P and sputtered TiN, Surface and Coatings Technology, 2010, Vol 204, p 2775-2781.

[72]Yuan X, Xie T, Wu G, Lin Y, Meng G and Zhang L; Fabrication of Ni-W-P nanowire arrays by electroless deposition and magnetic studies, Physica E: Low-dimensional Systems and Nanostructures, 2004, Vol 23, p 75-80.

[73]Tien S K, Duh J G and Chen Y I; Structure, thermal stability and mechanical properties of electroless Ni-P-W alloy coatings during cycle test, Surface and Coatings Technology, 2004, Vol 177, p 532-536.

[74]Balaraju J and Rajam K; Electroless deposition of Ni-Cu-P, Ni-W-P and Ni-W-Cu-P alloys, Surface and Coatings Technology, 2005, Vol 195, p 154-161.

[75]Sha W, Mohd Zairin H J and Wu X; SEM-EDX of morphology of electroless nickel coatings with tin and tungsten, Microscopy and Analysis, 2010, Vol 24 (5), p 13-16 (EU), 1114 (AM, AP).

[76]Sukkasi S, Sahapatsombut U, Sukjamsri C, Saenapitak S and Boonyongmaneerat Y; Electroless Ni-based coatings for biodiesel containers, Journal of Coatings Technology and Research, 2011, Vol 8, p 141-147.

[77]Liu H, Viejo F, Guo R, Glenday S and Liu Z; Microstructure and corrosion performance of laser-annealed electroless Ni-W-P coatings, Surface and Coatings Technology, 2010, Vol 204, p 1549-1555.

[78]Wang S L; Studies of electroless plating of Ni-Fe-P alloys and the influences of some deposition parameters on the properties of the deposits, Surface and Coatings Technology, 2004, Vol 186, p 372-376.

[79]Tai F, Wang K and Duh J; Application of electroless Ni-Zn-P film for under-bump metallization on solder joint, Scripta Materialia, 2009, Vol 61, p 748-751. 
[80]Duhin A, Sverdlov Y, Feldman Y and Shacham-Diamand Y; Electroless deposition of NiWB alloy on p-type Si (1 0 0 $)$ for NiSi contact metallization, Electrochimica Acta, 2009, Vol 54, p 6036-6041.

[81]Pang J, Li Q, Wang W, Xu X and Zhai J; Preparation and characterization of electroless Ni-Co-P ternary alloy on fly ash cenospheres, Surface and Coatings Technology, 2011, Vol 205, p 4237-4242.

[82]Chivavibul P, Enoki M, Konda S, Inada Y, Tomizawa T and Toda A; Reduction of core loss in non-oriented (NO) electrical steel by electroless-plated magnetic coating, Journal of Magnetism and Magnetic Materials, 2011, Vol 323, p 306-310.

[83]Parker K; Effects of heat treatment on the properties of electroless nickel deposits, Plating and Surface Finishing, 1981, Vol 68, p 71-77.

[84]Keong K G, Sha W and Malinov S; Computer modelling of the non-isothermal crystallization kinetics of electroless nickel-phosphorus deposits, Journal of Non-crystalline Solids, 2003, Vol 324, p 230-241.

[85]Krishnaveni K, Sankara Narayanan T and Seshadri S; Electroless Ni-B coatings: preparation and evaluation of hardness and wear resistance, Surface and Coatings Technology, 2005, Vol 190, p 115-121.

[86]Stallman K and Speckhardt H; Metalloberfl. Agnew. Elektrochem, 1981, Vol 35, p 979.

[87]Keong K G and Sha W; crystallisation and phase transformation behaviour of electroless nickel - phosphorus deposits and their engineering properties, Surface Engineering, 2002, Vol 18, p 329-343.

[88]Keong K G, Sha W and Malinov S; Hardness evolution of electroless nickel-phosphorus deposits with thermal processing, Surface and Coatings Technology, 2003, Vol 168, p 263274. 
[89]Yan M, Ying $\mathrm{H}$ and Ma T; Improved microhardness and wear resistance of the asdeposited electroless Ni-P coating, Surface and Coatings Technology, 2008, Vol 202, p 59095913.

[90]Baudrand D; Electroless nickel plating, ASM Handbook Volume 5: Surface engineering, p 290-310, (ASM International, Materials Park, OH, 1994).

[91]Dennis J K and Such T E; Nickel and chromium plating, (Woodhead Pub Ltd, 1993).

[92]Sahoo P; Wear behaviour of electroless Ni-P coatings and optimization of process parameters using Taguchi method, Materials \& Design, 2009, Vol 30, p 1341-1349.

[93]Sahoo P; Friction performance optimization of electroless Ni-P coatings using the Taguchi method, Journal of Physics D: Applied Physics, 2008, Vol 41, 095305.

[94]Hiratsuka K, Abe Y and Kawashima S; Effect of in-situ electroless plating on friction and wear of metals, Wear, 2003, Vol 255, p 910-916.

[95]Randin J and Hintermann H; Electroless Nickel deposited at controlled pH-Mechanical properties as a function of phosphorus content, Plating, 1967, Vol 54, p 523-532.

[96]Gawne D and Ma U; Friction and wear of chromium and nickel coatings, Wear, 1989, Vol 129, p 123-142.

[97]Davis J R; ASM Handbook Desk Edition, p 1521, (ASM International, Materials Park, $\mathrm{OH}, 1998)$.

[98]Song L, Song S and Zhao J; Preparation and corrosion resistance of $\mathrm{NiP} / \mathrm{TiO}_{2}$ composite film on carbon steel in sulfuric acid solution, Acta Metallurgica Sinica (English Letters), 2006, Vol 19, p 117-123.

[99]Guglielmi N; Kinetics of the deposition inert particles from electrolytic baths, J. Electrochem. Soc. 1972, Vol 119, p 1009-1012. 
[100]Grosjean A, Rezrazi M and Bercot P; Some morphological characteristics of the incorporation of silicon carbide (SiC) particles into electroless nickel deposits, Surface and Coatings Technology, 2000, Vol 130, p 252-256.

[101]Dini J; Perspective on plating for precision finishing, Plating and Surface Finishing, 1992, Vol 79, p 121-128.

[102]Reddy V, Ramamoorthy B and Nair P K; A study on the wear resistance of electroless Ni-P/diamond composite coatings, Wear, 2000, Vol 239, p 111-116.

[103]Apachitei I, Duszczyk J, Katgerman L and Overkamp P; Electroless Ni-P composite coatings: the effect of heat treatment on the microhardness of substrate and coating, Scripta Materialia, 1998, Vol 38, p 1347-1353.

[104]Li Y; Investigation of electroless Ni-P-SiC composite coatings, Plating and Surface Finishing, 1997, Vol 84, p 77-81.

[105]Grosjean A, Rezrazi M, Takadoum J and Bercot P; Hardness, friction and wear characteristics of nickel-SiC electroless composite deposits, Surface and Coatings Technology, 2001, Vol 137, p 92-96.

[106]Zhang Y, Wu Y, Sun K and Yao M; Characterization of electroless Ni-P-PTFE composite deposits, Journal of Materials Science Letters, 1997, Vol 17, p 119-122.

[107]Kalantary M, Holbrook K and Wells P; Optimisation of a bath for electroless plating and its use for the production of nickel-phosphorus-silicon carbide coatings, Transactions of the Institute of Metal Finishing, 1993, Vol 71, p 55-61.

[108]Xiang Y, Zhang J and Jin C; Study of electroless Ni-P-Nanometer diamond composite coatings, Plating and Surface Finishing, 2001, Vol 88, p 64-67.

[109]Pushpavanam M; Electroless Ni-P- $\mathrm{Al}_{2} \mathrm{O}_{3}$ composites, Bulletin of Electrochemistry, 1992, Vol 8, p 399. 
[110]Balaraju J and Seshadri S; Preparation and characterization of electroless Ni-P and NiP-Si ${ }_{3} \mathrm{~N}_{4}$ composite coatings, Transactions of the Institute of Metal Finishing, 1999, Vol 77, p 84-86.

[111]Abdel Hamid Z and Abou Elkhair M; Development of electroless nickel-phosphorus composite deposits for wear resistance of 6061 aluminum alloy, Materials Letters, 2002, Vol 57, p 720-726.

[112]Moonir-Vaghefi S, Saatchi A, Hejazi J; Deposition and properties of electroless nickelphosphorus-molybdenum disulfide composites, Metal Finishing, 1997, Vol 95, p 46.

[113]Ger M D and Hwang B J; Effect of surfactants on codeposition of PTFE particles with electroless Ni-P coating, Materials Chemistry and Physics, 2002, Vol 76, p 38-45.

[114]Izzard M and Dennis J; Deposition and properties of electroless nickel/graphite coatings, Transactions of the Institute of Metal Finishing, 1987, Vol 65, p 85-89.

[115]Grosjean A, Rezrazi M and Tachez M; Study of the surface charge of silicon carbide (SiC) particles for electroless composite deposits: nickel-SiC, Surface and Coatings Technology, 1997, Vol 96, p 300-304.

[116]Ger M D, Hou K H and Hwang B J; Transient phenomena of the codeposition of PTFE with electroless Ni-P coating at the early stage, Materials Chemistry and Physics, 2004, Vol 87, p 102-108.

[117]Mafi I R and Dehghanian C; Comparison of the coating properties and corrosion rates in electroless Ni-P/PTFE composites prepared by different types of surfactants, Applied Surface Science, 2011, Vol 257, p 8653-8658.

[118]Chen W, Gao W and He Y; A novel electroless plating of $\mathrm{Ni}-\mathrm{P}-\mathrm{TiO}_{2}$ nano-composite coatings, Surface and Coatings Technology, 2010, Vol 204, p 2493-2498.

[119]Dennis J, Sheikh S and Silverstone E; Electroless composite coatings for wear resistant applications, Transactions of the Institute of Metal Finishing, 1981, Vol 59, p 118-122. 
[120]Bozzini B, Martini C, Cavallotti P and Lanzoni E; Relationships among crystallographic structure, mechanical properties and tribological behaviour of electroless Ni-P $(9 \%) / B_{4} \mathrm{C}$ films, Wear, 1999, Vol 225, p 806-813.

[121]Pena-Munoz E, Berçot P, Grosjean A, Rezrazi M and Pagetti J; Electrolytic and electroless coatings of Ni-PTFE composites: Study of some characteristics, Surface and Coatings Technology, 1998, Vol 107, p 85-93.

[122]Straffelini G, Colombo D and Molinari A; Surface durability of electroless Ni-P composite deposits, Wear, 1999, Vol 236, p 179-188.

[123] Yu L G and Zhang X S; The friction and wear properties of electroless Nipolytetrafluoroethylene composite coating, Thin Solid Films, 1994, Vol 245, p 98-103.

[124]Łoiewicz B, Stepien A, Gierlotka D and Budniok A; Composite layers in Ni-P system containing $\mathrm{TiO}_{2}$ and PTFE, Thin Solid Films, 1999, Vol 349, p 43-50.

[125]Balaraju J, Sankara Narayanan T and Seshadri S; Structure and phase transformation behaviour of electroless Ni-P composite coatings, Materials Research Bulletin, 2006, Vol 41, p 847-860.

[126]Balaraju J and Rajam K; Electroless deposition and characterization of high phosphorus; $\mathrm{Ni}-\mathrm{P}-\mathrm{Si}_{3} \mathrm{~N}_{4}$ composite coatings, International Journal of Electrochemical Science, 2007, Vol 2, p 747-761.

[127]Apachitei I, Tichelaar F, Duszczyk J and Katgerman L; The effect of heat treatment on the structure and abrasive wear resistance of autocatalytic NiP and NiP-SiC coatings, Surface and Coatings Technology, 2002, Vol 149, p 263-278.

[128]Jiaqiang G, Lei L, Yating W, Bin S and Wenbin H; Electroless Ni-P-SiC composite coatings with superfine particles, Surface and Coatings Technology, 2006, Vol 200, p 58365842. 
[129]Huang Y, Zeng X, Annergren I and Liu F; Development of electroless NiP-PTFE-SiC composite coating, Surface and Coatings Technology, 2003, Vol 167, p 207-211.

[130]Wang L Y, Tu J, Chen W, Wang Y, Liu X, Olk C, Cheng D and Zhang X; Friction and wear behavior of electroless Ni-based CNT composite coatings, Wear, 2003, Vol 254, p 1289-1293.

[131]Le N O A, Staia M H and Hintermann H E; Influence of the heat treatment on the tribological behavior of a Ni-P-BN (h) autocatalytic composite coating, Surface and Coatings Technology, 1999, Vol 120, p 641-645.

[132]Dong D, Chen X, Xiao W, Yang G and Zhang P; Preparation and properties of electroless Ni-P-SiO 2 composite coatings, Applied Surface Science, 2009, Vol 255, p 70517055.

[133]Ranganatha S, Venkatesha $\mathrm{T}$ and Vathsala K; Development of electroless Ni-ZnP/nano- $\mathrm{TiO}_{2}$ composite coatings and their properties, Applied Surface Science, 2010, Vol 256, p 7377-7383.

[134]Balaraju J and Rajam K; Electroless ternary Ni-W-P alloys containing micron size $\mathrm{Al}_{2} \mathrm{O}_{3}$ particles, Surface and Coatings Technology, 2010, Vol 205, p 575-581.

[135]Petrova M, Noncheva Z and Dobreva E; Electroless deposition of diamond powder dispersed nickel-phosphorus coatings on steel substrate, Transactions of the Institute of Metal Finishing, 2011, Vol 89, p 89-94.

[136]Halling J; Principles of tribology, (MacMillan Education Ltd, London, 1975).

[137]Ebdon P; Composite electroless Nickel/PTFE coatings, Surface Engineering, 1987, Vol 3, p 114-116.

[138]Ebdon P; The performance of electroless nickel/PTFE composites, Plating and Surface Finishing, 1988, Vol 75, p 65-68. 
[139]Nishira M and Takano O; Friction and wear characteristics of electroless Ni-P-PFTE composite coatings, Plating and Surface Finishing, 1994, Vol 81, p 48-50.

[140]Ramalho A and Miranda J; Friction and wear of electroless NiP and NiP+PTFE coatings, Wear, 2005, Vol 259, p 828-834.

[141]Chen W X, Tu J P, Xu Z, Tenne R, Rosenstveig R, Chen W L and Gan H Y; Wear and friction of Ni-P electroless composite coating including inorganic fullerene- $\mathrm{WS}_{2}$ nanoparticles, Advanced Engineering Materials, 2002, Vol 4, p 686-690.

[142]Metzger W and Florian T; The deposition of dispersion hardened coatings by means of electroless nickel, Transactions of the Institute of Metal Finishing, 1976, Vol 54, p 174.

[143]Parker K; Hardness and wear resistance tests of electroless Ni deposits, Plating, 1974, Vol 61, p 834-841.

[144]Broszeit E; Mechanical, thermal and tribological properties of electro-and chemodeposited composite coatings, Thin Solid Films, 1982, Vol 95, p 133-142.

[145]Chen $\mathrm{C}$, Feng $\mathrm{H}$, Lin $\mathrm{H}$ and Hon $\mathrm{M} \mathrm{H}$; The effect of heat treatment on the microstructure of electroless Ni-P coatings containing SiC particles, Thin Solid Films, 2002, Vol 416, p 31-37.

[146]Duncan R; Hardness and wear resistance of electroless nickel-teflon composite coatings, Metal Finishing, 1989, Vol 87, p 33-34.

[147]Leon O, Staia M and Hintermann H; Wear mechanism of Ni-P-BN(h) composite autocatalytic coatings, Surface and Coatings Technology, 2005, Vol 200, p 1825-1829.

[148]Leon O, Staia M and Hintermann H; High temperature wear of an electroless Ni-P-BN (h) composite coating, Surface and Coatings Technology, 2003, Vol 163, p 578-584.

[149]Winowlin Jappes J T, Ramamoorthy B and Kesavan Nair P; Novel approaches on the study of wear performance of electroless Ni-P/diamond composite deposites, Journal of Materials Processing Technology, 2009, Vol 209, p 1004-1010. 
[150]Balaraju J, Sankara Narayanan T and Seshadri S; Evaluation of the corrosion resistance of electroless Ni-P and Ni-P composite coatings by electrochemical impedance spectroscopy, Journal of Solid State Electrochemistry, 2001, Vol 5, p 334-338.

[151]Jin H M, Jiang S H and Zhang L N; Microstructure and corrosion behavior of electroless deposited Ni-P/CeO 2 coating, Chinese Chemical Letters, 2008, Vol 19, p 13671370.

[152]Zuleta A A, Galvis O A, Castaño J G, Echeverría F, Bolivar F J, Hierro M P, PérezTrujillo F J; Preparation and characterization of electroless Ni-P-Fe $\mathrm{O}_{4}$ composite coatings and evaluation of its high temperature oxidation behaviour, Surface and Coatings Technology, 2009, Vol 203, p 3569-3578.

[153]Zhao Q, Liu Y and Abel E; Effect of $\mathrm{Cu}$ content in electroless Ni-Cu-P-PTFE composite coatings on their anti-corrosion properties, Materials Chemistry and Physics, 2004, Vol 87, p 332-335.

[154]Bozzini B, Sidorov V, Dovgopol A and Birukov J; Magnetic susceptibility of electroless $\mathrm{Ni}_{84} \mathrm{P}_{16}$ and $\mathrm{Ni}_{84} \mathrm{P}_{16}-\mathrm{B}_{4} \mathrm{C}$, International Journal of Inorganic Materials, 2000, Vol 2, p 437-442. [155]Tao P, Mei-Hua M, Fei-Bo X and Xin-Quan X; XPS and AES investigation of nanometer composite coatings of Ni-P-ZnX on steel surface $\left(\mathrm{ZnX}=\mathrm{ZnSnO}_{3}, \mathrm{Zn}_{3}\left(\mathrm{PO}_{4}\right)_{2}\right.$, $\mathrm{ZnSiO}_{3}$ ), Applied Surface Science, 2001, Vol 181, p 191-195.

[156]Yang Z, Xu H, Shi Y L, Li M K, Huang Y and Li H L; The fabrication and corrosion behavior of electroless Ni-P-carbon nanotube composite coatings, Materials Research Bulletin, 2005, Vol 40, p 1001-1009.

[157]Sarret M, Miller C and Amell A; Electroless NiP micro-and nano-composite coatings, Surface and Coatings Technology, 2006, Vol 201, p 389-395.

[158]Agarwala R, Sharma R; Electroless Ni-P nano coating technology, Synthesis and Reactivity in Inorganic, Metal-Organic and Nano-Metal Chemistry, 2008, Vol 38, p 229-236. 
[159]Agarwala R C; Electroless Ni-P-ferrite composite coatings for microwave applications, Pramana, 2005, Vol 65, p 959-965.

[160]Rabizadeh $\mathrm{T}$ and Allahkaram S R; Corrosion resistance enhancement of Ni-P electroless coatings by incorporation of nano- $\mathrm{SiO}_{2}$ particles, Materials \& Design, 2011, Vol 32, p 133-138.

[161]Chen W, Tu J, Xu Z, Chen W, Zhang X and Cheng D; Tribological properties of Ni-Pmulti-walled carbon nanotubes electroless composite coating, Materials Letters, 2003, Vol 57, p 1256-1260.

[162]Ang L M, Hor T S A, Xu G Q, Tung C, Zhao S and Wang J L S; Electroless plating of metals onto carbon nanotubes activated by a single-step activation method, Chemistry of Materials, 1999, Vol 11, p 2115-2118.

[163]Khoperia T; Electroless deposition in nanotechnology and ULSI, Microelectronic Engineering, 2003, Vol 69, p 384-390.

[164]Dinh C T, Nguyen T D, Kleitz F and Do T O; Shape-controlled synthesis of highly crystalline titania nanocrystals, ACS Nano, 2009, Vol 3, p 3737-3743.

[165]Cheng Z, Xu J, Zhong H and Song J; A modified electroless route to monodisperse and uniform nickel nanoparticle, Materials Chemistry and Physics, 2011, Vol 131, p 4-7.

[166]Chen Y, Cao M, Xu Q and Zhu J; Electroless nickel plating on silicon carbide nanoparticles, Surface and Coatings Technology, 2003, Vol 172, p 90-94.

[167]Osaka T, Takano N and Komaba S; Fabrication of nickel dots using selective electroless deposition on silicon wafer, Chemistry Letters, 1998, (7), 657-658.

[168]Takano N, Hosoda N, Yamada T and Osaka T; Effect of oxidized silicon surface on chemical deposition of nickel on n-type silicon wafer, Electrochimica Acta, 1999, Vol 44, p 3743-3749. 
[169]Niwa D, Homma T and Osaka T; Deposition mechanism of Ni on Si (100) surfaces in aqueous alkaline solution, Journal of Physical Chemistry B, 2004, Vol 108, p 9900-9904.

[170]Gasparac R, Kohli P, Mota M O, Trofin L and Martin C R; Template synthesis of nano test tubes, Nano Letters, 2004, Vol 4, p 513-516.

[171]Azizi A, Mohammadi M and Sadrnezhaad S; End-closed NiCoFe-B nanotube arrays by electroless method, Materials Letters, 2011, Vol 65, p 289-292.

[172]Lo C C, Huang C C, Liu C M, Chen C, Kuo C Y, Lin H J and Tseng Y C; Magnetic properties of electroless-deposited $\mathrm{Ni}$ and $\mathrm{Ni}-\mathrm{NiO}$ core-shell nano-arrays, Journal of Magnetism and Magnetic Materials, 2011, Vol 323, p 1950-1953.

[173]Shi Z and Walker A V; Synthesis of nickel nanowires via electroless nanowire deposition on micropatterned substrates, Langmuir, 2011, Vol 27, p 11292-11295.

[174]Hsueh H Y, Huang Y C, Ho R M, Lai C H, Makida T and Hasegawa H; Nanoporous gyroid nickel from block copolymer templates via electroless plating, Advanced Materials, 2011, Vol 23, p 3041-3046.

[175]Li W, Jin H, Hao Y, Chen T, Dai J and Wang Q; The microstructure of Ni layer on single-walled carbon nanotubes prepared by an electroless coating process, Journal of Nanomaterials, 2011, 348958.

[176]Seidel R, Liebau M, Duesberg G S, Kreupl F, Uuger E, Graham A P, Hoenlein W and Pompe W; In-situ contacted single-walled carbon nanotubes and contact improvement by electroless deposition, Nano Letters, 2003, Vol 3, p 965-968.

[177]Tsai T K, Chuang C C, Chao C G and Liu W L; Growth and field emission of carbon nanofibers on electroless Ni-P alloy catalyst, Diamond and Related Materials, 2003, Vol 12, p 1453-1459.

[178]Sugimura H, Hanji T, Takai O, Masuda T and Misawa H; Photolithography based on organosilane self-assembled monolayer resist, Electrochimica Acta, 2001, Vol 47, p 103-107. 
[179]Krupke R, Hennrich F, Weber H, Kappes M and Lhneysen H; Simultaneous deposition of metallic bundles of single-walled carbon nanotubes using ac-dielectrophoresis, Nano Letters, 2003, Vol 3, p 1019-1023.

[180]Chen M S, Brandow S L, Schull T L, Chrisey D B and Dressick W J; A non-covalent approach for depositing spatially selective materials on surfaces, Advanced Functional Materials, 2005, Vol 15, p 1364-1375.

[181]Fujikawa S and Kunitake T; Surface fabrication of hollow nanoarchitectures of ultrathin titania layers from assembled latex particles and tobacco mosaic viruses as templates, Langmuir, 2003, Vol 19, p 6545-6552.

[182]Knez M, Sumser M, Bittner A M, Wege C, Jeske H, Martin T P and Kern K; Spatially selective nucleation of metal clusters on the tobacco mosaic virus, Advanced Functional Materials, 2004, Vol 14, p 116-124.

[183]Li D and Yang C L; Acidic electroless copper deposition on aluminum-seeded ABS plastics, Surface and Coatings Technology, 2009, Vol 203, p 3559-3568.

[184]Li D, Goodwin K and Yang C L; Electroless copper deposition on aluminum-seeded ABS plastics, Journal of Materials Science, 2008, Vol 43, p 7121-7131.

[185]Tang X, Cao M, Bi C, Yan L and Zhang B; Research on a new surface activation process for electroless plating on ABS plastic, Materials Letters, 2008, Vol 62, p 1089-1091. [186]Seeb C K R, Esrom H, Charbonnier M, Romand M and Kogelschatz U; Surface modification of polyimide using dielectric barrier discharge treatment, Surface and Coatings Technology, 2001, Vol 142, p 455-459.

[187]Tang X, Bi C, Han C and Zhang B; A new palladium-free surface activation process for Ni electroless plating on ABS plastic, Materials Letters, 2009, Vol 63, p 840-842. 
[188]Garcia A, Berthelot T, Viel P, Jgou P and Palacin S; 3D amino-induced electroless plating: A powerful toolset for localized metallization on polymer substrates, ChemPhysChem, 2011, Vol 12, p 2973-2978.

[189]Lu Y, Xue L and Li F; Adhesion enhancement between electroless nickel and polyester fabric by a palladium-free process, Applied Surface Science, 2011, Vol 257, p 3135-3139.

[190]Huang C Y, Mo W W and Roan M L; Studies on the influence of double-layer electroless metal deposition on the electromagnetic interference shielding effectiveness of carbon fiber/ABS composites, Surface and Coatings Technology, 2004, Vol 184, p 163-169. [191]Charbonnier M, Goepfert Y, Romand M and Leonard D; Electroless plating of glass and silicon substrates through surface pretreatments involving plasma-polymerization and grafting processes, Journal of Adhesion, 2004, Vol 80, p 1103-1130.

[192]Zhai G, Yu W, Kang E, Neoh K, Huang C and Liaw D; Functionalization of hydrogenterminated silicon with polybetaine brushes via surface-initiated reversible additionfragmentation chain-transfer (RAFT) polymerization, Industrial \& Engineering Chemistry Research, 2004, Vol 43, p 1673-1680.

[193]Chen Y, Kang E, Neoh K and Huang W; Electroless metallization of glass surfaces functionalized by silanization and graft polymerization of aniline, Langmuir, 2001, Vol 17, p 7425-7432.

[194]Ng W K, Wu L and Moran P M; Microcontact printing of catalytic nanoparticles for selective electroless deposition of metals on nonplanar polymeric substrates, Applied Physics Letters, 2002, Vol 81, p 3097-3099.

[195]Li Y, Chen D, Lu Q, Qian X, Zhu Z and Yin J; Selective electroless deposition of copper on polyimide surface by microcontact printing, Applied Surface Science, 2005, Vol 241, p 471-476. 
[196]Fayet P, Granzer F, Hegenbart G, Moisar E, Pischel B and Wste L; Latent-image generation by deposition of monodisperse silver clusters, Physical Review Letters, 1985, Vol 55, p 3002-3004.

[197]Kimura M, Yamagiwa H, Asakawa D, Noguchi M, Kurashina T, Fukawa T and Shirai $\mathrm{H}$; Site-selective electroless nickel plating on patterned thin films of macromolecular metal complexes, ACS Applied Materials \& Interfaces, 2010, Vol 2, p 3714-3717.

[198]Kilicarslan A, Toptan F and Kerti I; Electroless nickel-phosphorus coating on boron carbide particles, Materials Letters, 2012, Vol 176, p 11-14.

[199] Takács D, Sziráki L, Török T I, Sólyom J, Gácsi Z, Gál-Solymos K; Effects of pretreatments on the corrosion properties of electroless Ni-P layers deposited on AlMg2 alloy, Surface and Coatings Technology, 2007, Vol 201, p 4526-4535.

[200]Sudagar J, Venkateswarlu K and Lian J; Dry sliding wear properties of a 7075-T6 aluminum alloy coated with Ni-P (h) in different pretreatment conditions, Journal of Materials Engineering and Performance, 2010, Vol 19, p 810-818.

[201]Puchi-Cabrera E S, Villalobos-Gutiérrez C, Irausquín I, La Barbera-Sosa J and Mesmacque G; Fatigue behavior of a 7075-T6 aluminum alloy coated with an electroless NiP deposit, International Journal of Fatigue, 2006, Vol 28, p 1854-1866.

[202]Gray J E and Luan B; Protective coatings on magnesium and its alloys-a critical review Journal of Alloys and Compounds, 2002, Vol 336, p 88-113.

[203]Sakata Y; Electroless nickel plating directly on magnesium alloy die castings, The Proceedings of the 74th AESF Annual Technical Conference. Orlando: AESF. 1987, p. 1-6. [204]Crotty D, Steinecket C and Durkin B; Plating difficult substrates with electroless nickel, Products Finishing, 1996, Vol 60, p 44-49.

[205]Brown L; UK company leads the way in magnesium plating, Finishing, 1994, Vol 18, p 22-23. 
[206]Corley P; Magnesium magic, Finishing, 1995, Vol 19, p 26.

[207]Toshinobu O, Chiyoko E and Yuji S; Plating method of magnesium and magnesium alloy, (JP61067770, 1986).

[208]Sharma A; Electrodeposition of gold on magnesium-lithium alloys, Metal Finishing, 1988, Vol 86, p 33-34.

[209]Sharma A; Gold plating on magnesium-lithium alloys, Metal Finishing, 1991, Vol 89, p 16-17.

[210]Sharma A, Suresh M, Bhojraj H, Narayanamurthy H and Sahu R; Electroless nickel plating on magnesium alloy, Metal Finishing, 1998, Vol 96, p 10-18.

[211]Reiners G and Griepentrog M; Hard coatings on magnesium alloys by sputter deposition using a pulsed dc bias voltage, Surface and Coatings Technology, 1995, Vol 76, p 809-814.

[212]Zhao H, Huang Z and Cui J; A novel method of electroless plating on AZ31 magnesium alloy sheet, Journal of Materials Processing Technology, 2008, Vol 203, p 310-314.

[213]He Y, Fu H, Li X and Gao W; Microstructure and properties of mechanical attrition enhanced electroless Ni-P plating on magnesium alloy, Scripta Materialia, 2008, Vol 58, p 504-507.

[214]Zhao H, Huang Z and Cui J; A new method for electroless Ni-P plating on AZ31 magnesium alloy, Surface and Coatings Technology, 2007, Vol 202, p 133-139.

[215]Iranipour N, Khosroshahi R.A and Ahmadi N.P; A study on the electroless Ni-P deposition on WE43 magnesium alloy, Surface and Coatings Technology, 2010, Vol 205, p 2281-2286.

[216]Ozdemir T, Oztin C and Kincal N; Treatment of waste pickling liquors: Process synthesis and economic analysis, Chemical Engineering Communications, 2006, Vol 93, p 548-563. 
[217]Grebenyuk V, Sorokin G, Verbich S, Zhiginas L, Linkov V, Linkov N and Smit J; Combined sorption technology of heavy metal regeneration from electroplating rinse waters, Water SA, 1996, Vol 22, p 381-384.

[218]Bacon G and Mihaylov I; Solvent extraction as an enabling technology in the nickel industry, Journal of the South African Institute of Mining and Metallurgy, 2002, Vol 102, p 435-443.

[219]Fairweather W; Electroless nickel plating of magnesium, Transactions of the Institute of Metal Finishing, 1997, Vol 75, p 113-117. 